Eastern Illinois University

The Keep

Masters Theses

Student Theses \& Publications

$1-1-2011$

\title{
Familial factors and attachment styles of male and female adult children of alcoholics
}

Kristina M. Decker

Eastern Illinois University

This research is a product of the graduate program in Psychology at Eastern Illinois University. Find out more about the program.

\section{Recommended Citation}

Decker, Kristina M., "Familial factors and attachment styles of male and female adult children of alcoholics" (2011). Masters Theses. 872.

http://thekeep.eiu.edu/theses/872

This Thesis is brought to you for free and open access by the Student Theses \& Publications at The Keep. It has been accepted for inclusion in Masters Theses by an authorized administrator of The Keep. For more information, please contact tabruns@eiu.edu. 
*****US Copyright Notice $e^{* * * * *}$

No further reproduction or distribution of this copy is permitted by electronic transmission or any other means.

The user should review the copyright notice on the following scanned image(s) contained in the original work from which this electronic copy was made.

Section 108: United States Copyright Law

The copyright law of the United States [Title 17, United States Code] governs the making of photocopies or other reproductions of copyrighted materials.

Under certain conditions specified in the law, libraries and archives are authorized to furnish a photocopy or other reproduction. One of these specified conditions is that the reproduction is not to be used for any purpose other than private study, scholarship, or research. If a user makes a request for, or later uses, a photocopy or reproduction for purposes in excess of "fair use," that use may be liable for copyright infringement.

This institution reserves the right to refuse to accept a copying order if, in its judgment, fulfillment of the order would involve violation of copyright law. No further reproduction and distribution of this copy is permitted by transmission or any other means. 


\section{THESIS MAINTENANCE AND REPRODUCTION CERTIFICATE}

TO: Graduate Degree Candidates (who have written formal theses)

SUBJECT: Permission to Reproduce Theses

The University Library is receiving a number of request from other institutions asking permission to reproduce dissertations for inclusion in their library holdings. Although no copyright laws are involved, we feel that professional courtesy demands that permission be obtained from the author before we allow these to be copied.

PLEASE SIGN ONE OF THE FOLLOMNG STATEMENTS:

Booth Library of Eastern Illinois University has my permission to lend my thesis to a reputable college or university for the purpose of copying it for inclusion in that institution's library or research holdings.

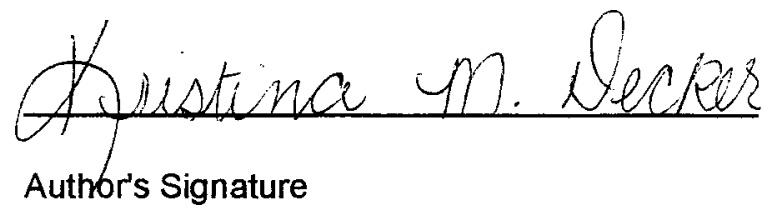

Author's Signature

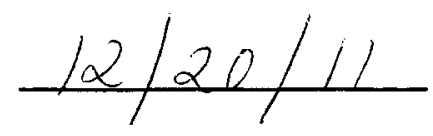

Date

I respectfully request Booth Library of Eastern Illinois University NOT allow my thesis to be reproduced because:

Author's Signature

Date

This form must be submitted in duplicate. 
FAMILIAL FACTORS AND ATTACHMENT STYLES OF MALE AND FEMALE ADULT CHILDREN OF ALCOHOLICS

$$
\text { BY }
$$

KRISTINA M. DECKER

THESIS PROPOSAL

SUBMITTED IN PARTIAL FULLFILLMENT OF THE REQUIREMENTS FOR THE DEGREE Of

MASTER OF ARTS

IN THE GRADUATE SCHOOL, EASTERN ILLINOIS UNIVERSITY

CHARLESTON, ILLINOIS

2011

I HEREBY RECOMMEND THAT THIS THESIS PROPOSAL BE ACCEPTED AS FULLFILLING THIS PART OF THE GRADUATE DEGREE CITED ABOVE

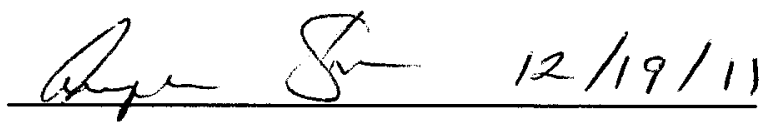

THESIS COMMITTEE CHAIR DATE

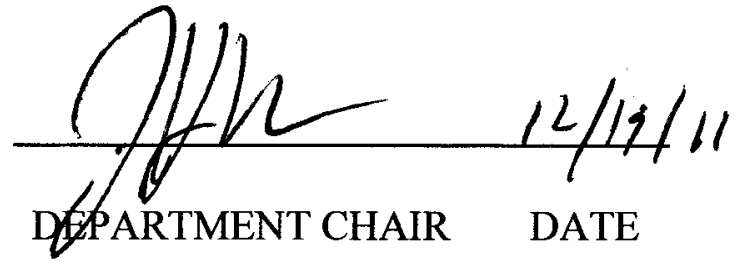

DATE

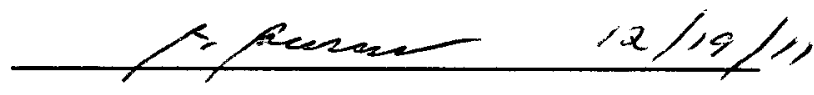

THESIS COMMITTEE MEMBER DATE

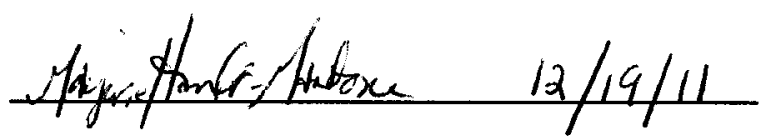

THESIS COMMITTEE MEMBER DATE 
Familial Factors and Attachment Styles of Male and Female Adult Children of

\author{
Alcoholics \\ Kristina Decker \\ Eastern Illinois University
}

December 19, 2011 


\begin{abstract}
In the United States, alcohol use disorders represent some of the most prevalent mental health disorders. Research has begun to explore parental alcoholism and its impact on children and families. The present study sought to examine the relationship between parental alcoholism and adult attachment styles in adult children of alcoholics (ACOAs), as well as the relationship with several familial factors such as gender of the alcoholabusing parent, family cohesion, family satisfaction, parent-child attachment, physical abuse, and verbal abuse. A sample of 223 college students completed a series of measures on parental alcoholism, family cohesion, family satisfaction, parent-child attachment, self-esteem, physical abuse, and verbal abuse. Based on endorsement of parental alcoholism through a yes/no demographic question or the total score on the Children of Alcoholics Screening Test, participants were categorized as either ACOA or non-ACOA. It was hypothesized and supported that ACOA participants would report more insecure attachment in adult relationships, more physical and verbal abuse, more insecure parentchild attachment, less family cohesion, and less family satisfaction than non-ACOAs. These factors (i.e., family satisfaction, family cohesion, parent child attachment, verbal abuse and physical abuse) were also predictors of adult relationship attachment among ACOAs accounting for $22 \%$ of the variance. Furthermore, less attachment with fathers and presence of verbal abuse were most predictive of insecure adult attachment among ACOAs. The differential impact of alcohol-abusing parent gender on family factors and an outcome variable was also explored and partially supported. Results indicated that ACOAs with two substance abusing parents experienced significantly more physical abuse, more verbal abuse, and less family satisfaction than ACOAs with either a
\end{abstract}


substance using father or mother. Finally, it was predicted and supported that family cohesion, family satisfaction, parent-child attachment, and verbal abuse would mediate the relationship between ACOA status and adult attachment style. Family satisfaction, parent-child attachment, and verbal abuse, therefore, buffer the potential negative impact of parental alcoholism on long-term offspring adjustment. Suggestions for future research and clinical implications are also discussed. 


\section{Acknowledgements}

I would like to express my sincerest appreciation to all of the people who have supported and encouraged me throughout this project. I would particularly like to thank Dr. Sharma for her incredible patience, understanding, insight, and encouragement and my other committee members, Dr. Bernas and Ms. Hanft-Martone, for their guidance and valuable contributions. I would also like to thank Mr. Daniel Harvey, the creator of Survey Central, who devoted incredible time to ensure successful data collection and management. Finally, thank you to my family for their never-ending encouragement, reassurance, and stress-relief while completing my thesis. 


\section{Table of Contents}

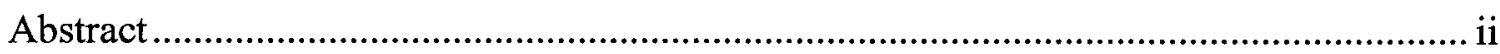

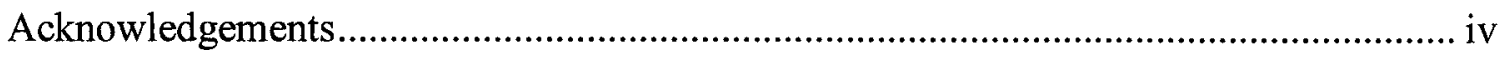

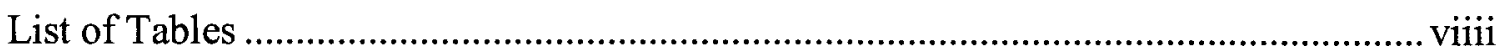

List of Appendices .............................................................................................. ix

Adult Children of Alcoholics................................................................................ 2

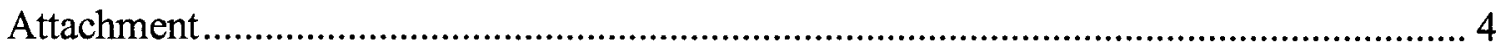

Attachment styles......................................................... 4

Attachment in alcoholic families and in ACOA relationships.......................6

Child maltreatment in alcoholic homes ............................................................. 9

Physical and sexual abuse.....................................................

Verbal abuse...................................................................

Long-term effects of verbal abuse.......................................... 15

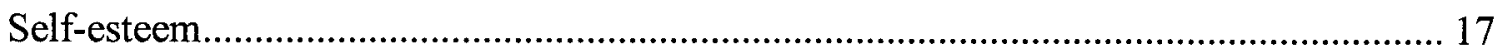

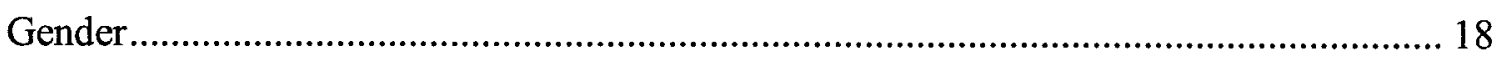

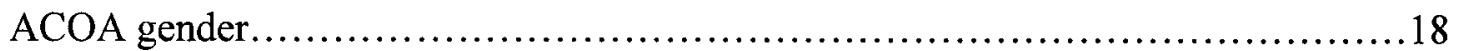

Gender and parent-child relationships......................................20

Gender of the alcohol-abusing parent....................................... 21

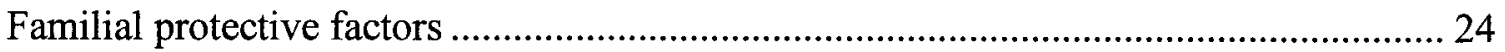

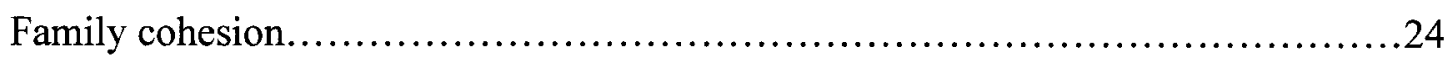

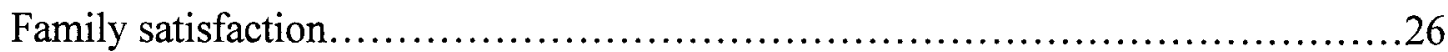

Parent-child attachment................................................27

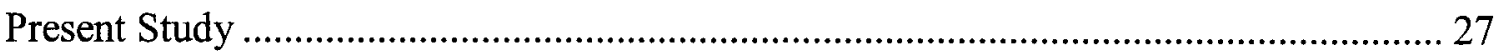




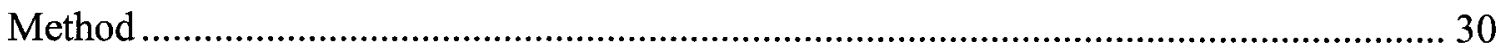

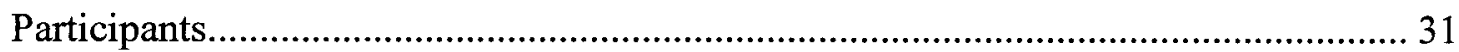

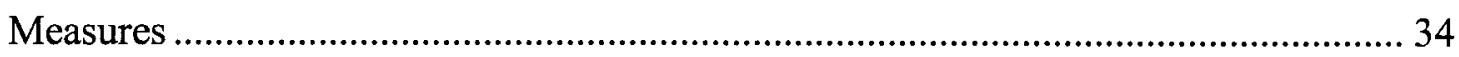

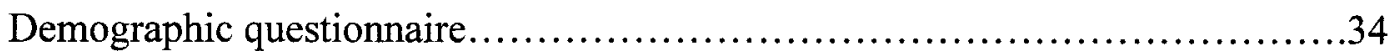

Parental alcoholism question..............................................34

Children of Alcoholics Screening Test.........................................34

Attachment Style Questionnaire..........................................35

Parent-Child Conflict Tactics Scale...........................................36

Psychological Maltreatment Scale ..........................................37

Family Adaptability and Cohesion Evaluation Scales IV.......................37

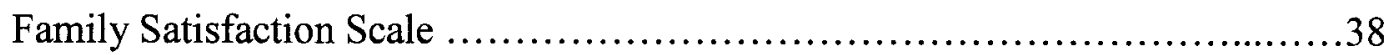

Parental Attachment Questionnaire............................................39

Rosenberg Self-Esteem Scale.............................................40

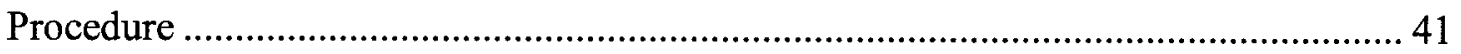

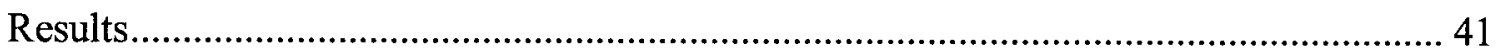

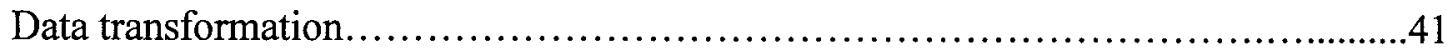

Parental alcoholism and adult relationship attachment style........................42

Parental alcoholism and self-esteem................................................43

Parental alcoholism and familial factors.......................................43

Parental alcoholism and abuse.................................................4

Predictors of adult relationship attachment style........................................................45

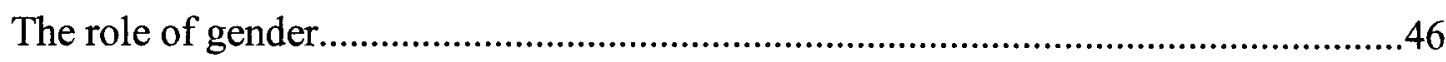

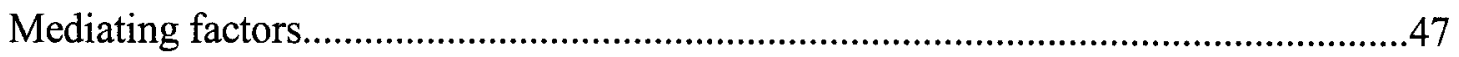




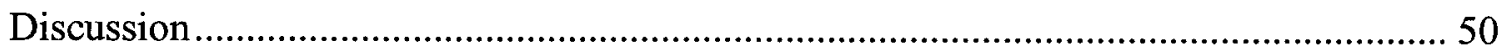

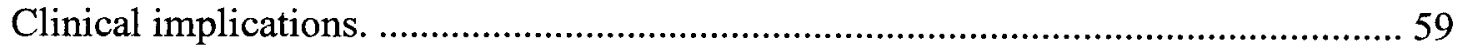

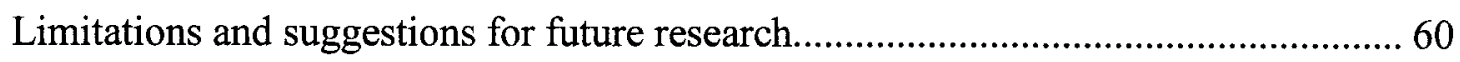

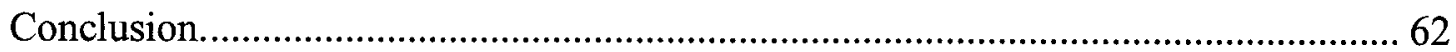

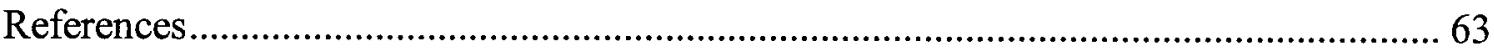




\section{List of Tables}

1. Demographic Variables for ACOA and Non-ACOA Participants....................76

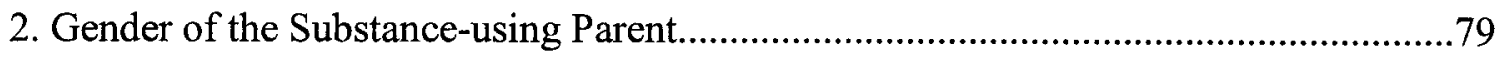

3. Group Differences in Adult Relationship Attachment Style........................80

4. Group Differences in Familial Factors......................................................81

5. Intercorrelations for CAST, FSS, FACES IV, PAQ, PMS and CTSPC...............82

6. Group Differences in Parental Abuse Behaviors....................................83

7. Predictors of Adult Relationship Attachment Style..................................84

\section{List of Figures}

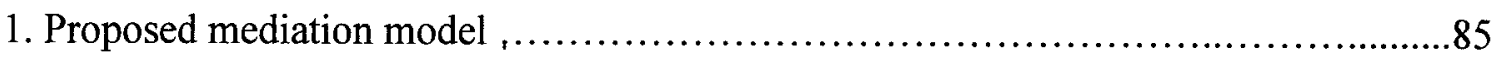

2. Family cohesion as partial mediator...................................................86

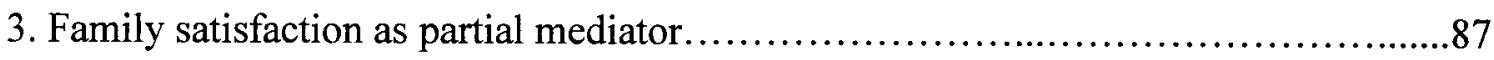

4. Maternal parent-child attachment as partial mediator..................................88

5. Paternal parent-child attachment as partial mediator.................................89

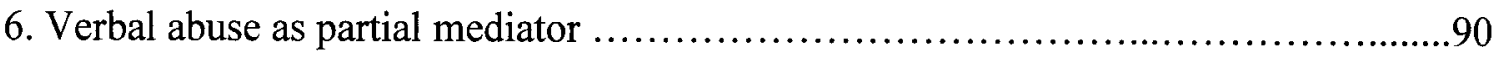




\section{List of Appendices}

A. Demographic Questionnaire.................................................91

B. Children of Alcoholics Screening Test (CAST)...................................93

C. Attachment Style Questionnaire (ASQ) ........................................95

D. Parent-Child Conflict Tactics Scale (CTSPC) ..................................97

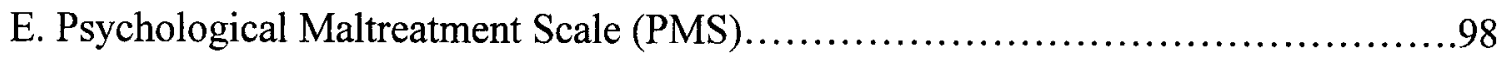

F. Family Adaptability and Cohesion Evaluation Scales (FACES IV)...................99

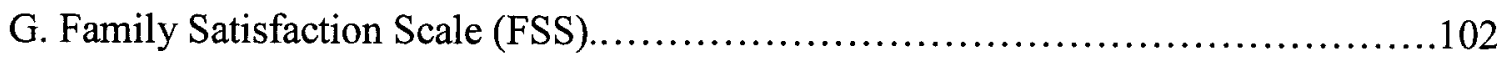

H. Parental Attachment Questionnaire (PAQ) ..................................103

I. Rosenberg Self-Esteem Scale (RSE)...........................................106

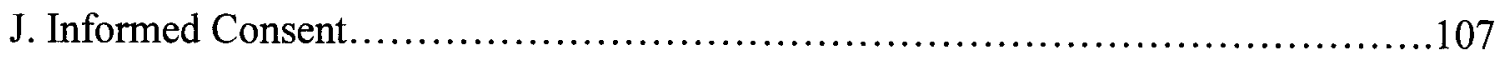


Familial Factors and Attachment Styles of Male and Female

Adult Children of Alcoholics

In the United States, alcohol use disorders represent some of the most prevalent mental health disorders (Grant, Dawson, Stinson, Chou, Dufour, \& Pickering 2006; World Health Organization, 2004). Unfortunately, analysis of the National Institute on Alcohol Abuse and Alcoholism's (NIAAA) 1991-1992 National Longitudinal Alcohol Epidemiologic Survey (NLAES) and their 2001-2002 National Epidemiologic Survey on Alcohol and Related Conditions (NESARC) revealed that prevalence of adult alcohol abuse has increased significantly between 1991-1992 and 2001-2002 (Grant et al., 2006). According to results from the 2010 National Survey on Drug Use and Health (NSDUH) 23.1 percent of the U.S. population aged 12 and older participate in binge drinking while 6.7 percent engage in heavy drinking (SAMHSA, 2011). Binge drinking was defined as five or more drinks on the same occasion on at least one day in the past 30 days. Heavy drinking was defined as five or more drinks on five or more days in the past 30 days (SAMHSA, 2011). Additionally, NSDUH reports that prevalence of substance dependence or abuse has remained stable from 2002 at 8.5 percent to 2010 at 8.7 percent (SAMHSA, 2011).

While such disorders have negative effects on the affected individual, they also impact the subsystems in which the person lives and interacts. Specifically, in the United States, one in four children is exposed to an alcohol use disorder in their family (Grant et al., 2006). In families with an alcoholic parent, parental impairment may lead to increased environmental stressors such as financial hardship, job loss, and divorce. Such environmental stressors have been suggested to have a destabilizing impact on the family, 
thus contributing to familial dysfunction and chaos (Hussong, Bauer, Huang, Chassin, Sher, \& Zucker, 2008). Brown (1988) also identified numerous maladaptive features in alcoholic families such as lack of nurturance, emotional and physical abuse, and neglecting children's feelings. Eiden, Chavez, and Leonard (1999) examined interaction between alcoholic fathers and their infants and discovered that alcoholic fathers displayed lower levels of sensitivity, positive affect, and verbalization during play-time than nonalcoholic fathers. It is suggested that this less sensitive, more negative parenting style substantially contributes to childhood dysfunction.

Given the potentially severe effects of parental alcoholism on children and the family, recent research has placed substantial focus on the long-term clinical impact of parental alcoholism on adult children of alcoholics (ACOA). Adult children of alcoholics (ACOA) are defined as adults whose family of origin consisted of at least one parent or guardian with an alcohol abuse or dependence problem (Jaeger, 2000; Jones, 2007; Lease, 2002).

\section{Adult Children of Alcoholics}

For two decades, investigation of ACOAs has continuously expanded. Much of the early literature empirically examined ACOA characteristics that clinicians had identified when working with ACOAs (Lease, 2002). Research has identified a variety of negative outcomes among ACOAs such as increased depression, increased anxiety disorders, antisocial behavior, behavioral undercontrol, increased problematic substance abuse, low self-esteem, and more difficulty with intimacy and dependency (Black, Bucky, \& Wilder-Padilla, 1986; Lewis Harter, 2000; Sher, Walitzer, Wood, \& Brent, 1991; Sheridan \& Green, 1993). In contrast with current trends, much of the early 
literature featured ACOAs as a homogenous group with distinctive characteristics (Kerr \& Hill, 1992).

It is important to note, however, that the ACOA literature is somewhat inconsistent. A number of studies have found no differences between ACOAs and their non-ACOA peers in terms of maladaptive adjustment (Bidaut-Russell, Smith, \& Bradford, 1994; Harter \& Taylor, 2000; Johnson \& Rasmussen, 2006). Additionally, some research has also claimed that ACOAs are not clinically distinct from other adult children of dysfunctional families (Fisher, Jenkins, Harrison, \& Jesch, 1992; Harrington \& Metzler, 1997). These results negate, in part, the classification of ACOAs as a distinct clinical group apart from families experiencing non-alcoholic dysfunction. Harrington and Metzler (1997) also found significant dissatisfaction with problem-solving communication in intimate relationships among adult children from both dysfunctional and dysfunctional-alcoholic families. Additionally, these researchers found no difference in trust or degree of global distress between adults who had or had not experienced dysfunction in childhood.

In addition to addressing common individual ACOA features and outcomes, research has also explored common dynamics in alcoholic families such as high dysfunction, higher divorce rates, low amounts of family cohesion, low levels of physical and verbal expressions of positive feelings, low levels of family competence, low levels of relationship satisfaction, and higher levels of abuse (Black et al., 1986; Johnson, 2001; Kerr \& Hill, 1992; Sheridan, 1995; Sheridan \& Green, 1993). Specifically regarding abuse, alcoholism in the family is associated with higher levels of physical, sexual, and emotional abuse toward the spouse and child (Johnson, 2001). 
While continuing to investigate similar ACOA familial and individual characteristics, recent literature has begun examining how these factors contribute to the heterogeneity of ACOA family experience and psychological outcomes. Lease (2002) posits that alcoholic families fall along a continuum of dysfunction based on environmental and experiential differences. It is suggested that protective and mediating factors contribute to this variability and even absence of adverse outcomes for ACOAs (Rangarajan, 2008). Following this change in perspective, many researchers are investigating non-clinical ACOA populations to gain more insight into the diversity of outcomes and possible resiliency characteristics among ACOAs (Beesley \& Stoltenberg, 2002; Stout \& Mintz, 1996).

\section{Attachment}

Attachment styles. Given the empirical support for interpersonal difficulties among ACOAs, recent literature has shown an increased interest in the role of attachment on ACOA outcomes (Jaeger, Hahn, \& Welnraub, 2000; Kelley, French, Schroeder, Bountress, Stewart, Steer, \& Cooke, 2008; Vungkhanching, Sher, Jackson, \& Parra, 2004). Exploration of ACOA attachment is rooted in fundamental theories of attachment as discussed by Bowlby (1969; 1973), Ainsworth, Blehar, Water, and Wall (1978), and Hazan and Shaver (1987). Bowlby (1973) posited that infants exhibit attachment behavior with the primary caregiver with the ultimate goal being proximity maintenance. Based on behavioral observations and interactions with the primary caregiver, the infant develops an internal model of expectations of how the caregiver will respond to the infant's needs. This internal model guides attachment behavior (Jaeger et al., 2000). Bowlby (1973) further defined infant-caregiver attachment and theorized that infants who 
feel that an attachment figure is available to readily meet the infant's needs are more confident and feel safe to explore their environment, thus displaying a model of secure attachment. The alternative, therefore, is that an infant who is not confident that their attachment figure will meet their needs will experience insecure attachment, which is characterized by anxiety, fear, and anger. Bowlby (1973) then contends that this perception of availability of attachment figures builds up or breaks down the child's confidence throughout infancy, early childhood, and adolescence. The infant-caregiver attachment, therefore, is thought to remain relatively stable throughout the child's lifetime. Bowlby's (1973) theory also suggests that the perceptions and beliefs about caregiver availability that children develop accurately indicate their actual childhood experience.

Fitting in with Bowlby's (1973) attachment theories, Ainsworth et al. (1978) defined three specific attachment styles that infants develop with their primary caregiver in response to the caregiver's responsiveness to the infant's needs. These attachment styles are anxious/ambivalent, avoidant, and secure. Ainsworth et al. (1978) described anxious/ambivalent attachment style as an anxious, fearful, non-exploratory infant who is distressed when the attachment figure is absent, but is hesitant to warm up to the figure upon return. This style is thought to be in response to the primary caregiver's inconsistent or delayed response to the infant's needs. Alternatively, infants who avoid their caregiver in response to the caregiver's rejection for physical contact characterize avoidant attachment style. Secure attachment is the alternative to these styles. This attachment style is characterized by a confident, physically and emotionally attentive infant- 
caregiver relationship, which promotes independence and exploration (Ainsworth et al., 1978).

Hazan and Shaver (1987) expanded upon Ainsworth et al. (1978) and Bowlby's (1973) theories and explored the theories' application to adult romantic relationships. Hazan and Shaver (1987) proposed that the attachment process and attachment styles in adult romantic relationships parallel those in infant-parent attachment. Based on Ainsworth et al.'s (1978) attachment theory, Hazan and Shaver (1987) identified three types of adult romantic relationship attachment: secure, anxious-ambivalent, and avoidant. In romantic relationships, secure adults have little concern about partner abandonment and grow close to and depend on others with ease and comfort. Anxiousambivalent individuals may worry that their partner doesn't love them and will leave the relationship. These individuals may also be hesitant to become close to people while also seeking an intense closeness, which may push people away. Finally, avoidant individuals may have difficulty and feel uncomfortable trusting and growing close to their partner (Hazan and Shaver, 1987). Consistent with Bowlby's (1973) perception that attachment perceptions remain constant throughout the lifetime, Hazan \& Shaver (1987) also theorized that relationship expectations and attachment styles developed in childhood continue with the child into adulthood and influence adult romantic relationship behavior.

Attachment in alcoholic families and in ACOA relationships. In recent studies of ACOAs, researchers have begun exploring the effects of parental alcoholism on ACOAs through attachment theory (Jaeger et al., 2000; Vungkhanching et al., 2004). It is hypothesized that growing up in an alcoholic family of origin results in dysfunctional interaction patterns in adulthood (Beesley \& Stoltenberg, 2002). Beesley and Stoltenberg 
(2002) contend that when conceptualized through an attachment theory framework, the problematic outcomes that ACOAs experience are indicative of "the lack of responsiveness and availability of the alcoholic parent as the child begins to create and assimilate a representational model of the self in relation to others" (p. 286). This parental lack of responsiveness and availability in ACOA families of origin maps onto Bowlby's (1973) concept of insecure attachment and Ainsworth et al.'s (1978) anxious-ambivalent and avoidant attachment styles (Jaeger et al., 2000).

With influence from Bowlby (1973), Ainsworth et al. (1978), and Hazan and Shaver (1987), many studies have begun investigating a hypothesis of dysfunctional ACOA relationship attachment outcomes, which are indicative of the infant-caregiver attachment style. Specifically regarding adult romantic attachment, studies have indicated that ACOAs are more likely to have insecure adult relationship attachments than their peers (Jaeger et al., 2000; Vungkhanching et al., 2004). Further, Jaeger et al. (2000) found that adult daughters of alcoholic fathers were significantly less secure in their adult relationships and more likely to have an insecure attachment than non-ACOA females (Jaeger et al., 2000). Although paternal alcoholism significantly impacted ACOA outcomes, it is important to acknowledge that Jaeger et al. (2000) did not examine the impact of alcoholic mothers in this study, which they note as an area for future study. Jaeger et al. (2000) specifically chose to examine daughters with alcoholic fathers because literature supports higher frequencies of alcoholic fathers and female ACOA participants in existing literature. They, therefore, thought that focusing on these demographics would be most relevant to and consistent with observations in earlier literature (Jaeger et al., 2000). 
Additionally, Jaeger et al. (2000) suggest that future studies should also consider whether or not the alcohol-abusing parent is the primary caregiver. Because women tend to be the primary caregiver, children of alcoholic mothers may display increased problematic outcomes and relationships when compared to children of alcoholic fathers and non-ACOAs (Jaeger at al., 2000).

A limited number of studies have examined both attachment style and relationship functioning or satisfaction among ACOAs. Brennan, Shaver, and Tobey (1991) found that ACOAs were more like to have avoidant or anxious-ambivalent attachment styles when compared to non-ACOAs. Kelly, Nair, Rawlings, Cash, Steer, and Fals-Stewart (2005) found that college student ACOAs reported significantly more insecure parentchild attachment and avoidant and anxious romantic attachment than their non-ACOA peers. In a longitudinal study of married couples, parental alcoholism was significantly related to lower marital satisfaction (Kearns-Bodkin \& Leonard, 2008). Although the association between parental alcoholism and insecure attachment was significant for ACOA husbands, no significant relationship existed for wives.

Inconsistency regarding attachment of ACOAs was noted in Kelley et al. (2008). Their results indicated that college female ACOAs with alcohol abusing/dependent mothers reported significantly lower relationship qualities, such as warmth, sensitivity, consistency, and support, which frequently correlate with insecure attachment style (Kelley et al., 2008). In the same study, however, ACOAs with an alcohol abusing/dependent fathers did not report any significant differences from their nonACOA peers in terms of parent-child attachment (Kelley et al., 2008). This finding is inconsistent with Jaeger et al. (2000), which, as previously noted, supported a 
relationship between paternal alcohol abuse and insecure attachment style in female ACOAs. In attempting to identify why Kelley at al. (2008) and Jaeger et al. (2000) had such differing results it is important to note that both studies used collegiate female samples. Beesley and Stoltenberg (2002) found that although male and female ACOAs reported significantly less relationship satisfaction than their non-ACOA peers, there was no significant difference in attachment style between groups. The authors hypothesized this finding to be the result of resiliency among college ACOAs (Beesley \& Stoltenberg, 2002).

Given the inconsistency and scarcity of research regarding attachment outcomes among ACOAs, further research in this area is necessary to better understand long-term attachment outcomes. As previously mentioned, current research surrounding ACOA outcomes has focused on heterogeneity within the group. In exploring this heterogeneity, it is important to identify moderating factors, which may exacerbate dysfunctional ACOA adjustment or, alternatively, may protect and support functional ACOA adjustment. This study's examination of such factors is a continuation of an earlier study conducted by Konz (2009), hereafter referred to as Phase 1. The current study (Phase 2) will explore the influence of the following factors on the relationship between parental alcohol abuse and ACOA attachment style: parental verbal abuse, physical abuse, levels of family cohesion and family satisfaction, and perceived parent-child attachment. Additionally, Phase 2 will expand upon Phase 1 and examine the differential impact of gender, both of the alcohol-abusing parent and the child, on adult attachment style and the proposed familial factors.

\section{Child maltreatment in alcoholic homes}


Research has frequently cited co-occurrence of child abuse in homes with an alcohol- abusing parent. According to the World Health Organization (WHO, 2006), in $35 \%$ of parental child abuse cases, the offending parent had consumed either drugs or alcohol at the time of the incident. Researchers suggest that the presence of child abuse is another indicator of dysfunction in alcoholic homes (Johnson, 2000). Sheridan (1995) found significant relationships between presence of parental alcoholism, child abuse, and lowered family competence. Although research is inconsistent regarding the relationship between parental alcoholism and child abuse, much of the existing literature supports a significant relationship (Black et al., 1986; Johnson, 2001; Kerr \& Hill, 1992; Miller, Smyth, \& Mudar, 1999; Sheridan, 1995; Velleman, Templeton, Reuber, Klein, \& Moesgen, 2008). Generally, research has indicated that children growing up with an alcohol-abusing parent and experiencing abuse have increased potential for negative adult outcomes.

Alternatively, other studies have found limited support for increased child abuse in alcoholic homes (Harris, 2008; Harter \& Taylor, 2000). Harter \& Taylor (2000) found that college student ACOAs and non-ACOAs reported similar rates of sexual, physical, and emotional abuse. Also, when controlling for abuse history, parental alcoholism did not have a significant effect on adult maladjustment and distress. Parental alcoholism, however, interacted with emotional abuse history and heightened its effect on the ACOAs' social adjustment (Harter \& Taylor, 2000). The authors suggest that those with the most severe impairments may have been underrepresented due to the demands of earning a college degree. College students who have an alcohol abusing-parent, therefore, may represent a resilient group of ACOAs who display less severe impairments, thus 
explaining the study's contradictory outcome (Harter and Taylor, 2000). Harter and Taylor (2000) also hypothesize that reliance on samples more likely to present heightened distress and maladjustment (e.g., clinical, support group, or incarcerated samples) in previous research may explain the findings that ACOAs experience an increased incidence of childhood abuse (Kerr \& Hill, 1992; Miller at al., 1999; Sheridan, 1995)

Rather than examining ACOAs directly, Harris (2008) utilized a clinical sample of mothers receiving inpatient treatment for alcohol and addiction problems. While parental self-confidence was inversely related to child abuse, parental alcohol abuse did not elevate the likelihood or severity of child maltreatment (Harris, 2008). Given inconsistency within the literature and potential for negative adult outcomes, it is imperative to further investigate the interaction between parental abuse and child abuse history in the family of origin.

Typically, child maltreatment is separated into three distinct categories: physical abuse, sexual abuse, and psychological/emotional maltreatment. Given research support for differential impact among child abuse categories, this study will consider physical/sexual abuse and verbal abuse separately. As noted in Harter and Taylor (2000), literature investigating the long-term effects of different types of abuse is scarce. Unfortunately, few studies have examined the unique contributions of abuse and parental alcoholism to dysfunctional outcomes among ACOAs.

Physical and sexual abuse. Although a single operational definition does not exist, child physical abuse is typically classified as the intentional use of physical force that injures or has the potential to significantly impact and injure the child (Heyman \& Slep, 2006). Broadly, child sexual abuse is conceptualized as forced, coerced, or 
consensual sexual activity between an adult a child that is developmentally inappropriate for the child (Rodriguez-Srednicki \& Twaite, 2004; Sheridan, 1995). In families with an alcohol-abusing parent, children are more frequently exposed to physical and sexual abuse than children in families without alcohol abuse (Black et al., 1986; Kerr \& Hill, 1992; Walsh, MacMillan, \& Jamieson, 2003). Walsh et al. (2003) found that children of substance users were twice as likely as children of non-substance users to experience physical and sexual abuse, and that both types of abuse occurred at similar frequencies. Black et al. (1986) indicated that physical abuse was present not only when the alcohol abusing mother or father was intoxicated, but also in periods of nondrinking. Interestingly, all members of families with parental alcoholism displayed significantly more physically abusive behavior (Black et al., 1986). Regarding parent-child attachment outcomes and physical abuse, Finzi, Ram, Har-Even, Shnit, and Weizman (2001) found that children who were physically abused identified insecure attachment styles significantly more than non-abused children.

Looking solely at the long-term impact of physical and sexual abuse, numerous studies have identified significant maladaptive outcomes. Although Harter and Taylor (2000) found no significant relationship between history of abuse and history of parental alcoholism, they did note a significant increase in obsessive anxiety, general anxiety, hostility and somatization among students who had been physically or sexually abused. All three types of abuse were associated with increased interpersonal sensitivity, depression, paranoia, and psychotic symptoms (Harter \& Taylor, 2000). Examining abuse in a study of female college students, Briere and Runtz (1990) found that physical abuse was uniquely associated with externalized physical aggression. Sexual abuse, on the other 
hand, was associated primarily with dysfunctional sexual behavior (Briere \& Runtz, 1990).

Regarding the specific long-term impact of both physical/sexual abuse and parental alcohol abuse, limited literature exists. Kerr \& Hill (1992) noted that female ACOAs who had been sexually abused reported greater levels of familial dissatisfaction, especially regarding their parental relationships, when compared to their non-abused, non-ACOA peers. In examining adult psychological distress and symptomology among ACOAs, Melchert (2000) found that parental substance abuse, physical abuse, and sexual abuse accounted for significant amounts of variance in adult distress. Alternatively, Johnson and Rasmussen (2006) found that when abuse was controlled for, parental alcoholism status did not significantly predict adult depression or aggression. Such findings in the literature reinforce the need for further investigation of ACOA outcomes including abuse as a moderating variable.

Research has also supported that ACOAs more frequently witness parental spousal abuse (Johnson, 2001; Nicholas \& Rasmussen, 2006). Goddard and Bedi (2010) posit that witnessing intimate partner abuse may in itself be a form of child abuse given the relationship between partner abuse and maladaptive psychosocial and psychological outcomes children develop. Although this abuse dynamic was not explored in the current study, it may be a useful consideration in future research given the potential long-term impact of witnessing spousal abuse. Another, less frequently researched, aspect of abuse is verbal and psychological abuse, which is suggested to have considerable presence and impact in alcoholic homes. 
Verbal abuse. In attempting to operationally define verbal abuse, often used interchangeably with emotional or psychological abuse, much debate exists in literature (Moran, Bifulco, Ball, Jacobs, \& Benaim, 2002). Infante and Wigley (1986) conceptualized verbal abuse as one person attacking the self-concept of another in order to inflict psychological harm. According to Infante and Wigley (1986), verbally aggressive messages include teasing, insults, character attacks, and competence attacks. Egeland (2009) highlighted common key elements of emotional abuse such as taunting, belittling, and rejection. Specifically regarding child emotional abuse, Moran et al. (2002) proposed the following definition, which defines the construct in terms of both the abusive act and the potential for harm:

Psychological abuse is concerned with cruelty demonstrated by verbal and nonverbal acts, repeated or singular, intended or not, from a close other in a position of power or responsibility over the child. These have the potential for damaging the social, cognitive, emotional, or physical development of the child and are demonstrated by behaviors, which are humiliating/degrading, terrorizing, extremely rejecting, depriving of basic needs or valued objects inflicting marked distress/discomfort, corrupting/exploiting, cognitively disorientation or emotionally blackmailing. (p. 220)

Because research investigating verbal abuse is limited, it is suggested that prevalence figures are underreported (Egeland, 2009). In the Administration for Children and Families' 2009 annual child maltreatment report, around 50,000 psychological maltreatment cases were reported, which is $7.6 \%$ of all reported child maltreatment cases. Despite lack of accurate prevalence figures, as previously noted, ACOA research has 
indicated substantial co-occurrence between parent- child verbal abuse and parental alcoholism.

Long-term effects of verbal abuse. Compared to physical and sexual abuse, verbal abuse has received less attention in empirical research (Egeland, 2009; Nicholas \& Rasmussen, 2006), which Egeland (2009) attributes to the assumption that the less obvious effects of verbal abuse are also less severe. A growing body of research, however, demonstrates the considerably detrimental effects of verbal abuse. As addressed in many of the following studies, although verbal abuse frequently co-occurs with physical and sexual abuse, research indicates its unique contribution to outcome variance.

Regarding immediate outcomes of emotional abuse, among a community sample of adolescents, Shaffer, Yates and Egeland (2009) found that childhood emotional abuse uniquely contributed to adolescent social withdrawal and lowered socioemotional competence. In a clinical sample of abusive families, Ney (1987), found that verbally abused children were more likely to be aggressive toward the self, to have a pessimistic view of the world, to run away from home, and to attempt suicide. The author posited that when compared to other types of abuse, verbal abuse is particularly destructive because the individual's self-definition is attacked, thus resulting in altered, pessimistic views of the future and the world, producing "deeper" long-term conflict (Ney, 1987).

Numerous studies have also explored the impact of verbal abuse history on adult psychopathology symptomology. The presence of depressive symptoms in adults with a history of experiencing emotional abuse is consistently supported across various samples in previous research (Bilfulco, Moran, Baines, Bunn \& Stanford, 2002; Gross \& Keller, 1992; O’Dougherty, Crawford, \& Del Castillo, 2009; Nicholas \& Rasmussen, 2006). 
Gross and Keller (1992) found history of emotional abuse among college students to be a critical variable in predicting not only levels of depression, but also attributional style. In a sample of college students, O'Dougherty et al. (2009) found that emotional abuse and neglect significantly predicted adult symptoms of depression and anxiety even after controlling for other child abuse experiences. Bilfulco et al. (2002) explored a community-based sample and found that psychological abuse predicted lifetime recurrent major depressive disorder.

In addition to exploring adult psychopathology among individuals with a verbal abuse history, researchers have also investigated the impact on adult romantic relationships and attachment. Among university students, Weber and Patterson (1997) found a negative relationship between maternal verbal aggression in childhood and perceptions of cohesion in adult romantic relationships. Roberto, Carlyle, Goodall, and Castle (2009) found that college students reporting secure romantic attachment perceived their parents as significantly less verbally aggressive than participants with non-secure attachment styles. Similarly, Riggs and Kaminski (2010) found that childhood emotional abuse directly predicted insecure adult attachment in a sample of college students. Given the frequent co-occurrence of parental alcoholism and verbal abuse and both parental alcoholism's and verbal abuse's demonstrated influence on adult attachment, it is critical to examine verbal abuse as a mediating factor in the present study.

As previously noted with physical and sexual abuse, little research exists which examines the impact of both parental alcoholism and verbal/psychological abuse on adult functioning. Within that literature, results are inconsistent. Harter and Taylor (2000) found that college students who had experienced both emotional abuse and parental 
alcoholism displayed the poorest school and work role functioning when compared to students who had experienced other forms of abuse with or without parental alcoholism. Nicholas and Rasmussen (2006) found that emotional abuse from fathers was an important predictor of depressive symptoms and aggression among daughters. When researchers controlled for abuse, however, ACOA status did not significantly predict depressive symptoms or aggression (Nicholas \& Rasmussen, 2006). This outcome, therefore, supports the necessity to examine verbal abuse as mediating factor potentially exacerbating dysfunctional adjustment among ACOAs.

\section{Self-esteem}

In their discussions of attachment, both Bowlby (1973) and Hazan and Shaver (1987) suggest a relationship between self-esteem and attachment. As previously noted, Bowlby (1973) contends that the perception of availability of attachment figures builds up or breaks down the child's confidence throughout infancy, early childhood, and adolescence. Similarly, Hazan and Shaver (1987) suggest that self-esteem along with attachment patterns remains stable and is reflected in adult attachment patterns.

Although current research addressing low self-esteem among ACOAs is limited, results indicate a relationship between parental alcoholism and low self-esteem (Bush, Ballard, \& Fremouw, 1995; Lease, 2002; Rangarajan, 2008; Rangarajan \& Kelly, 2006). Interestingly, Rangarajan (2008) found support for parental attachment as a mediator between parental alcoholism and ACOA self-esteem. After controlling for the effects of parental attachment, there was no observed effect of parental alcoholism on ACOA selfesteem, thus indicating parental attachment as a mediator. Rangarajan (2008) did note gender differences in her results. Specifically, parental attachment mediated the effect of 
paternal alcoholism on ACOA self-esteem but did not mediate the relationship between maternal alcoholism and ACOA self-esteem. Alternatively, Hall (2007) found no difference in self-esteem when comparing African American ACOAs to non-ACOAs in a university sample. As highlighted in many discussions of ACOA heterogeneity, Hall (2007) suggests that this sample of ACOAs may have experienced protective factors that allowed for resilient outcomes.

Also, given the suggested co-occurrence between parental-alcoholism and verbal abuse, it should be noted that Briere and Runtz (1990) and Gross and Keller (1992) found that verbal abuse was uniquely related to low self-esteem in adulthood (Briere \& Runtz, 1990; Downs \& Miller, 1998; Gross \& Keller, 1992; Leeson \& Nixon, 2010; Morimoto \& Sharma, 2004).

\section{Gender}

In recent research, the influence of gender in the ACOA family dynamic has also been investigated. Although studies' foci, methodology, and outcomes are varied, they do indicate significant gender differences, especially when examining the sex of the alcoholabusing parent. Clearly, the inconsistency in and scarcity of research in this area warrant future study. Additionally, exploring the differential impact of gender on ACOA outcomes, may expand knowledge of the reasons underlying the heterogeneity of ACOA outcomes.

ACOA gender. While a number of studies exist examining unique outcomes of female ACOAs, few studies have explored outcome differences between male and female ACOAs. Within those limited studies, none examined ACOA gender differences and long-term attachment outcomes. In the research, all-female samples are prevalent, thus 
revealing a gap in the literature, which under-represents male ACOAs and their long-term adjustment.

Despite the scarcity of literature, a few studies have explored gender differences with a number of adjustment variables. In a study exploring defined roles in alcoholic families, Veronie and Fruehstorfer (2001) revealed significant gender differences. Based on Wegscheider's (1989) family role identity theory, which defines four family roles in the alcoholic family (i.e., the hero, the scapegoat, the mascot, and the lost child) Veronie and Fruehstorfer (2001) found that male ACOAs were significantly more likely than female ACOAs to identify with "the mascot," which is categorized by wittiness and attention-seeking or indifferent behavior. Females, on the other hand, significantly identified more strongly with the "lost child." The "lost child" was characterized by emotional sensitivity, permissiveness, avoidance, and timidity (Veronie \& Fruehstorfer, 2001). The authors note that family interactions are typically models for adult peer interactions and relationships (Veronie \& Fruehstorfer, 2001). It is, therefore, hypothesized that gender differences observed in childhood may persist for ACOAs into their adult relationship interactions and attachments.

In a study of children of alcoholics (COAs; i.e., minors), Furtado, Laucht, and Schmidt (2006) found that female COAs (between the ages of 2-11) exhibited significantly more internalizing psychopathology symptoms such as phobias, anxiety, and depression between the ages 2-11. No gender differences, however, were observed in presentation of externalizing symptoms such as hyperactivity, aggressive behaviors, tantrums, and destructive behavior. It should be noted, though, that the COAs did present significantly more psychiatric symptoms than their non-COA peers (Furtado et al., 2006). 
In a clinical sample of ACOAs receiving treatment for a substance use disorder, Corte and Becherer (2007) also examined gender differences in psychopathology. Their results indicated that while ACOAs, in general, presented with significantly more symptoms of major depression, obsessive compulsive disorder, and generalized anxiety disorder than non-ACOAs, female ACOAs had significantly more depressive symptoms than male ACOAs while male ACOAs reported significantly more anxiety symptoms (Corte \& Becherer, 2007).

Alternatively, in a study of adult sons and daughters of alcoholic mothers, BidautRussell et al. (1994) found no significant gender differences in terms of lifetime psychiatric disorders. Consistent with this finding, Wright and Heppner (1991) examined college students and found no significant differences between female and male ACOAs on the five following variables: substance use, problem solving judgment, perceived social support, shame, and suicidal ideation. Wright and Heppner's (1991) results may be indicative of the suggested resiliency among collegiate ACOAs (Harter \& Taylor, 2000). Given these conflicting findings, additional research is necessary to clarify the impact of ACOA gender on long-term adjustment and further explore protective factors that may contribute to ACOA resiliency.

Gender and parent-child relationships. When discussing parent-child attachments, Bowlby's $(1969 ; 1973)$ theory conceptualized the primary attachment figure as someone who was readily available to the infant, who was most frequently conceptualized as the infant's mother. According to the U.S. Department of Labor (2004), while only $35 \%$ of mothers in 1965 were in the labor force, in $2004,71 \%$ of mothers were working. As Jacobs and Kelley (2006) found in dual income households 
with parents of a preschoolers, "the more hours mothers worked outside the home, the more accessible fathers were to their children, the more responsibility men took for childcare, and the more time fathers served as the child's primary caregiver" (p. 41). Logically, therefore, it could be assumed that because parents are more frequently sharing the role as primary caregiver, each plays a significant role in shaping children's attachment styles. Numerous studies, however, cite that mothers continue to assume more responsibility in childcare (Cabrera, Tamis-LeMonda, Bradley, Hofferth, \& Lamb, 2000; Jacobs and Kelley, 2006; Kelley, Braitman, Henson, Schroeder, Ladge, and Gumienny, 2010).

When considering gender differences in parent-child attachment and interactions, Starrel (1994) highlights that, although child-rearing is considered primarily the mother's domain, current trends in dual-earning families encourage an equal role from both husbands and wives. In a large, nationally representative sample, Starrel (1994) longitudinally explored gender-specific parental characteristics that influenced relationships with sons and daughters. Results indicated that fathers are typically less involved with daughters than mothers. Additionally, with daughters, fathers were significantly less nurturing than mothers, and daughters reported significantly closer relationships with their mothers. Although sons displayed greater similarity in their relationships with their mother and father than did daughters, sons also reported more closeness with fathers than with mothers.

Gender of the alcohol-abusing parent. Limited research exists examining the relationship between the alcohol abusing parent's gender and ACOA outcomes. While studies examining that relationship have indicated mixed results, it should be noted that 
within this limited research, studies vary considerably in their purpose and hypotheses. Although some studies investigate gender differences among all ACOAs, others specifically target female ACOAs or consider both the gender of the ACOA and the alcohol-abusing parent. Given these variances, it is difficult to critically assess trends and contradictions across studies. These findings, however, substantiate further exploration of gender differences among ACOAs.

In a study of parent-infant interactions and attachment, Eiden, Edwards, and Leonard (2002) found that paternal alcoholism was more strongly associated with poor quality infant-parent interactions and insecure parent-child attachments. Maternal drinking, however, was not significantly associated with insecure-attachment. Eiden et al. (2002) attribute this suprising outcome to the fact that the majority of mothers in the study reported light to moderate drinking habits with few alcohol problems. Eiden et al.'s (2002) findings suggest support for the influence of parent gender on ACOA attachment outcomes when considering infant-parent and adult romantic attachment theories (Bowlby, 1969; 1973; Hazan \& Shaver, 1987).

In a sample of college students, Kelley et al. (2010) hypothesized that because mothers are typically the primary child care provider and are considered to have a stronger attachment with their children than fathers, maternal alcohol abuse may have a greater impact on ACOAs relationships and depressive symptoms. Supporting this hypothesis, Kelley et al.'s (2010) results indicated that maternal substance abuse significantly predicted the quality of maternal and peer relationships, while paternal substance abuse predicted neither the quality of paternal nor peer relationships. Specifically, participants experiencing maternal alcohol abuse reported less trust, greater 
alienation, and poorer communication in peer and maternal relationships (Kelley et al., 2010). Alternatively, supporting the differentiated impact of paternal alcoholism, Stout and Mintz (1996) found that female college students with alcohol-abusing fathers indicated significantly more interpersonal problems than participants with alcoholabusing mothers and non-ACOAs. Additionally, participants with alcohol-abusing mothers did not differ significantly from non-ACOAs (Stout \& Mintz, 1996). Given these contradictory results, it is questioned whether adult ACOA attachment outcomes are less influenced by the gender of the parent and more influenced by the extent of the alcohol-abusing parent's role in care giving. Formulation of hypotheses in this area, however, is difficult given the lack of consistent results across studies and the limited amount of research.

In a longitudinal study of married couples, Kearns-Bodkin and Leonard (2008) examined the longitudinal impact of parental alcoholism on relationship functioning across their first four years of marriage. Interestingly, results indicated that participants' assessment of their marital relationship was related to alcoholism in the opposite gender parent (Kearns-Bodkin \& Leonard, 2008). To elaborate, husbands with an alcoholabusing mother reported lowered marital satisfaction than husbands without a history of maternal alcoholism while wives with paternal alcoholism reported lower levels of intimacy in the marriage than wives without a history of maternal alcoholism. KearnsBodkin and Leonard (2008) conjecture that the opposite-gender parent may have an integral role in influencing relationship skill building. They cite support from Mussen and Rutherford (1963) and Hetherington's (1976) studies, which found girls' development of appropriate sex-roles to be strongly motivated by the father-daughter relationship. 
Additionally, Hetherington (1972) found a relationship between inappropriate interactions with the opposite sex and decreased presence of the father among adolescent girls. Kearns-Bodkins and Leonard (2008), therefore, hypothesized that having an alcoholic parent of the opposite sex prevents both boys and girls from modeling and engaging in appropriate opposite gender interactions, thus hindering development of healthy adult relationships.

As previously noted, researchers' approach to examining gender differences among ACOAs is varied, but results indicate a necessity for further examination. Exploring gender, both of the ACOA and the alcohol-abusing parent, provides substantial opportunity to expand research on factors contributing to varied outcomes among ACOAs.

\section{Familial protective factors}

In the consideration of ACOAs as a heterogeneous group, many researchers have begun exploring the role of family protective factors in influencing the negative impact of parental alcoholism on adult outcomes. Clearly, numerous contradictions exist in the literature fuelling the debate over the validity of regarding ACOAs as a clinically distinct, homogenous category. Significant research also utilizes collegiate ACOA samples, which have been often referred to as a resilient sample in the ACOA population. This resiliency suggests the presence of protective factors that facilitate healthy adjustment. Such protective factors that have been explored or suggested are family cohesion, family attachment, and perceived parent-child attachment.

Family cohesion. Regarding cohesion, Roosa, Dumka, and Tein (1996) reason that families exhibiting high cohesion provide strong emotional bonds and support, which 
help members better cope with stressors, thus enabling healthy adjustment. It can, therefore, be presumed that increased levels of family cohesion will improve an alcoholic family's ability to cope with the stressors and associated dysfunction of having an alcohol-abusing parent, thus resulting in improved ACOA adjustment (Roosa et al., 1996). In their study of elementary-aged children, Roosa et al. (1996) explored the family dynamics of COAs and found that family cohesion mediated the impact of parental alcohol abuse on child mental health outcomes. High levels of family cohesion, therefore, mediated parental alcoholism and led to lower levels of depression and conduct disorder in COAs.

Similarly, Bijttebier, Goethals, and Ansoms (2006) found associations between parental alcohol abuse and low family cohesion. In their study, they assessed children's level of negative affect, feelings of competence, and self-esteem. The authors found that family cohesion mediated the relationship between parental alcohol abuse and the child's global self-worth (Bijttebier et al., 2006). Furthermore, in a sample of 6- to 12- year-olds, El-Sheikh and Buckhalt (2003) found family cohesion and adaptability to be a protective factor against social problems, externalizing symptoms, and internalizing symptoms that are linked to children of alcoholics.

When considering long-term outcomes of parental alcoholism in ACOAs, family cohesion is supported as a protective factor. In a sample of college students, Larson and Reddy (2004) examined the mediation effect of family process between parental alcoholism and quality of dating relationship. The quality of dating relationships was evaluated through the following factors: trust, commitment, and overall satisfaction. Family process was defined using three variables: family health or competency, family 
cohesion, and family conflict resolution (Larson \& Reedy, 2004). Although family cohesion was not isolated as a factor, results revealed family process as a mediator between parental alcoholism and dating relationship quality. Given the support for family cohesion as a single mediation factor between parental alcoholism and other commonly cited ACOA outcomes, it is reasonable to consider its effect substantial regarding relationship outcomes.

Family satisfaction. Currently, family satisfaction has not been formally examined among ACOAs. Carver and Jones (1992) operationally defined the construct as "the degree to which one is generally satisfied with one's family of origin and the constituent relationships imbedded therein (e.g., parent-child, siblings, etc.) " (p.72). Initial use of their devised scale, the Family Satisfaction Scale, revealed positive correlation between family satisfaction and satisfactory interpersonal relationships (Carver \& Jones, 1992). Barraca, Yarto, and Olea (2000) conceptualize family satisfaction not as a global evaluation of the family in comparison to the "ideal," but rather as a subjective, individual interpretation of feelings experienced during family interactions. What connects both of these conceptualizations of family satisfaction is that the construct is measured through individual perception.

It is reasonable to presume that the dysfunction in alcoholic homes is associated with unsatisfactory interpersonal relationships and, therefore, decreased family satisfaction. Prior to Phase 1 (Konz, 2009) of this study, family satisfaction had not been investigated in ACOA research. Given the likelihood of dysfunction in alcoholic homes, it is logical that children of alcoholics will perceive familial satisfaction differently than children raised with non-alcohol abusing parents. Based on the preliminary results from 
Phase 1, ACOAs reported significantly lower familial satisfaction than did non-ACOAs. Due to limited sample size in Phase 1, however, a mediating or moderating relationship could not be examined (Konz, 2009).

Parent-child attachment. Kerr and Hill (1992) found that ACOAs had significantly more negative perceptions of the quality of their relationships with parents than non-ACOAs. However, when specifically considering ACOAs' attachment with alcohol-abusing parents, results are inconsistent. It appears that ACOAs may be able to form healthy and secure attachments within their family despite negative perceptions of the relationships. In a study of university students, Rangarajan (2008) found support for parental attachment as a mediator between parental alcoholism effects and ACOA selfesteem. Especially in households with only one alcohol-abusing parent, it seems logical that the possible protective influence of positive attachment with the non-alcohol abusing parent may influence long-term outcomes.

As previously noted, Hazan and Shaver's (1987) adult romantic attachment theory is grounded in infant-caregiver attachment theory (Bowlby, 1969, 1973; Ainsworth et al., 1978) in that the attachments formed within the family of origin remain relatively stable throughout the lifespan and are transferred to adult romantic attachments. It could logically be assumed, therefore, that perception of parent-child attachment in the family of origin could serve as a protective factor in the relationship between parental alcoholism and adult relationship outcomes.

\section{Present Study}

Research on alcoholic families clearly indicates the presence of dysfunctional dynamics, which could influence potentially negative and detrimental outcomes in 
ACOAs. Research has not only supported a likelihood for increased mental health concerns among ACOAs, but also an increased incidence of physical, sexual, and emotional abuse. Recent trends in the ACOA literature have also given focus to the influence parental alcoholism has on the adult child's relationship functioning and attachment styles. While research is inconsistent in its support of this relationship, numerous studies have begun emphasizing the heterogeneous outcomes within ACOAs. Many recent research studies have moved away from attempting to define ACOAs as a distinct clinical category. Often, suggestions for future research focus on exploring those factors that contribute to within-group differences. As previously noted, research has identified samples of ACOAs who are resilient to the negative outcomes associated with experiencing parental alcoholism. Logically, therefore, it can be presumed that resilient ACOAs are exposed to certain protective factors (e.g., family cohesion, family satisfaction, and parent-child attachment), which contribute to positive adjustment.

As previously noted, this study is Phase 2 of an earlier study, which was Phase 1 (Konz, 2009). The aim of the present study is to continue investigation of factors that influence the relationship between parental alcoholism and ACOA outcomes. Specifically, this study seeks to examine the effect of the following factors on the relationship between parental alcoholism and adult offspring attachment style and parental alcoholism and adult offspring self-esteem: child abuse, ACOA gender, gender of the alcohol-abusing parent, level of family cohesion, family satisfaction, and parentchild attachment. 
While the original set of research questions and hypotheses remain unchanged, an additional question/hypothesis was included to examine the influence of gender. The current research questions and hypotheses are as follows:

Study Question 1: Do ACOAs differ from non-ACOAs with respect to the outcome variables of adult relationship attachment style and self-esteem? It is hypothesized that a significant relationship will be found between parental alcoholism and ACOA relationship attachment style. More specifically, ACOAs will demonstrate greater levels of insecure relationship attachment while non-ACOAs will report greater levels of secure relationship attachment. Given the limited and conflicting literature on the relationship between ACOA status and self-esteem, this portion of the research question is exploratory.

Study Question 2: Do ACOAs differ from non-ACOAs with respect to the proposed protective factors (i.e., family satisfaction, family cohesion, and parent-child attachment)? Prior research has identified the negative impact of familial dysfunction on these factors. Because parental alcoholism is often considered as family dysfunction, it can be presumed that such negative impact is also present in families with an alcoholabusing parent. It is, therefore, hypothesized that ACOAs will report lower levels of familial satisfaction and lower levels of family cohesion than non-ACOA participants. It is also hypothesized that ACOAs will report weaker bonds with parents overall when compared to non-ACOA participants. Regarding attachment specifically with the alcoholabusing parent, this research question remains exploratory.

Study Question 3: Do ACOAs experience more verbal and severe physical abuse from parental figures than children raised in a home where parental alcoholism was not 
present? Given support for the increased likelihood of child abuse (physical, sexual, and verbal) in homes with an alcohol-abuse parent, it is hypothesized that ACOAs will report greater instances of physical and verbal abuse in the family of origin than will nonACOAs.

Study Question 4: Which factor or combination of factors best predicts adult relationship attachment style and adult self-esteem in ACOA versus non-ACOA participants? Because no prior research has examined these factors in combination, this research question is exploratory. In phase 1 of this study (Konz, 2009), there were not enough participants to address this study question.

Study Question 5: Does ACOA gender and/or gender of the alcohol-abusing parent differentially impact the proposed family factors (i.e., family cohesion, family satisfaction, parent-child attachment, and verbal abuse) adult outcome variables (i.e., relationship attachment style and self-esteem)? Given the limited and inconsistent findings in current research, this research question is also exploratory.

Study Question 6: Do the proposed family factors (i.e., family cohesion, family satisfaction, parent-child attachment, and verbal abuse) mediate the relationship between ACOA experience and adult outcome variables (i.e., relationship attachment style and self-esteem)? It is hypothesized that family cohesion, family satisfaction, parent-child attachment, and verbal abuse will mediate the relationship between parental alcoholism and adult relationship attachment style. Given the limited literature on the relationship between the proposed protective factors and self-esteem, this portion of the research question is exploratory.

\section{Method}




\section{Participants}

In this study, participants were obtained from a mid-sized university in the Midwest. During Phase 1 (Konz, 2009) of the study, 84 college students participated. In that sample, participants ranged in age from 18 to 57 years $(M=20.0 ; S D=4.8)$ the majority of whom were females $(n=62 ; 74 \%)$. It should be noted that although 150 participants were initially recruited during this phase, due to completion errors, the data from only 84 participants could be used.

For the current study, an additional 232 participants were recruited, but due to completion errors, only the data from 177 participants could be used. When combined with the 84 participants from Phase 1, the resultant 261 participants were reduced to 223 participants to achieve more balanced distribution across male and female ACOA and non-ACOA groups. Of those final 223 participants, the age range was 18 to 38 years ( $M$ $=19.4 ; S D=2.2)$. Additionally, the sample consisted of $103(46 \%)$ men and $120(54 \%)$ women. The majority of participants $(n=133 ; 60 \%)$ were in their freshman year of college. Regarding ethnicity, $191(86 \%)$ participants were predominantly Caucasian $(\mathrm{n}=$ $191 ; 86 \%)$ and African American $(\mathrm{n}=21 ; 9 \%)$. For additional demographic data, see Table 1.

Based on participants' responses to demographic questions addressing parental alcohol misuse or participants' score on the Children of Alcoholics Screening Test (CAST; Pilat \& Jones, 1984/1985), participants were divided into two groups: ACOA or non-ACOA. Participants were included in the ACOA group if they indicated parental alcohol misuse on the demographic questionnaire or scored 6 or higher on the CAST. 
Of the 103 participants in the ACOA group, 60 (58\%) were women and $43(42 \%)$ were men. When considering gender of the substance-using parent, $59 \%(n=55)$ of ACOAs had substance-using fathers, $18 \%(\mathrm{n}=17)$ had substance-using mothers, and in $23 \%(n=21)$ both parents abused substances (see Table 2$)$. Only varying slightly from the overall sample, the age range among ACOAs was 18 to 38 years $(M=19.5 ; S D=$ 2.9). Additionally, the ACOA group was predominantly Caucasian $(\mathrm{n}=88 ; 85 \%)$ and African American ( $\mathrm{n}=10 ; 10 \%$; See Table 1). Like the overall sample, the majority of participants $(n=65 ; 63 \%)$ in the ACOA group were in their freshman year of college. Regarding their family structure during childhood, $36 \%(n=37)$ reported an intact family structure, $29 \%(n=30)$ reported having divorced single parents, and $21 \%(n=22)$ reported having divorced remarried parents. Of those participants with divorced or separated parents, the age at the time of divorce or separation ranged from 1 to 19 years $(M=9.2 ; S D=5.4)$.

Regarding substance use, $30 \%(n=31)$ reported having self-concerns about their own substance use while only $6 \%(n=6)$ reported receiving treatment for their substance use. Additionally, $25 \%(n=25)$ reported that at least one parent had received treatment for their substance misuse while $16 \%(n=16)$ reported that someone in their family had received treatment related to their parent's substance misuse. Furthermore when asked about their parents mental health concerns other than substance use or abuse, $26 \%(n=$ 23) of ACOA participants reported that their mother experienced significant mental health concerns while $18 \%(n=16)$ reported that their father experienced significant mental health concerns. Additionally, $17 \%(n=15)$ of participants reported that at least 
one of their parents had received treatment for their mental health concern. For additional ACOA demographic data see Table 1.

In the non-ACOA participant sample, $60(50 \%)$ were female and $60(50 \%)$ were male. Non-ACOA participants ranged in age from 18 to 25 years $(M=19.3 ; S D=1.4)$. Similar to the overall sample, the majority of non-ACOA participants $(n=68 ; 57 \%)$ were in their freshman year of college. Regarding ethnicity, the majority $(86 \%, \mathrm{n}=103)$ was Caucasian, followed by $9 \%(\mathrm{n}=11)$ who were African American. Regarding their family structure, $71 \%(\mathrm{n}=85)$ of non-ACOA participants reported an intact structure while only $12 \%(n=14)$ reported that their parents were divorced and single, and $7 \%(n=8)$ reported that their parents were remarried.

When asked about their own substance use, $10 \%(n=12)$ of the participants reported being concerned about their use while $3 \%(n=4)$ reported receiving treatment for their own substance use. Additionally, $11 \%(n=10)$ report receiving mental health treatment not related to substance use. With regard parental mental health not related to substance use, $9 \%(n=8)$ of non-ACOAs reported that their mother experienced significant mental health concerns while $1 \%(n=1)$ reported that their father had significant mental health concerns. Furthermore, $9 \%(n=8)$ reported that at least one of their parents received treatment for a non-substance related mental health concern.

Preliminary chi-square analyses revealed that ACOAs and non-ACOAs differed with regard to several variables. For example, non-ACOAs reported a higher frequency of intact family structure during childhood than ACOAs, $\chi^{2}(4, \mathrm{~N}=223)=30.21, p<$ .001. Additionally, ACOA participants were more likely to report higher frequency of concern regarding self-substance use, $\chi^{2}(1, \mathrm{~N}=223)=14.38, p<.001$. Finally, mothers 
$\left(\chi^{2}(2, \mathrm{~N}=177)=10.25, p<.01\right)$ and fathers $\left(\chi^{2}(1, \mathrm{~N}=177)=10.15, p<.01\right)$ of ACOA participants were more likely to experience significant mental health concerns outside of or in addition to substance misuse.

\section{Measures}

Demographic Questionnaire. Participants completed a demographic questionnaire containing items regarding participants' age, sex, ethnicity, education level, parental marital status, personal substance use/treatment history, parental substance use/treatment history, and personal and parental non-substance related mental health history (See Appendix A).

Parental Alcoholism Question. Participants were asked to evaluate whether or not they considered either or both of their parents to have experienced significant problems with alcohol use. The following yes/no questions were used to screen participants and group them with either ACOAs or non-ACOAs: "Did your mother experience significant problems with alcohol use?" "Did your father experience significant problems with alcohol use?"

Children of Alcoholics Screening Test (CAST). In addition to the parental alcoholism question, participants were classified as ACOA versus non-ACOA based on their responses to this 30-item measure (See Appendix B). Pilat and Jones (1984) developed the CAST to identify children or adult children with an alcoholic parent. The survey examines participants' emotions, attitudes, perceptions, and experiences regarding their parents' drinking practices. Additionally, the measure addresses participants' attempts to control parental drinking behavior, efforts to escape parental drinking, and exposure to alcohol related domestic violence (Pilat \& Jones, 1984). Participants 
responded to items with either "yes" or "no." A score of six or more positive endorsements classifies the participant as an ACOA. Scores of zero or one indicate that the participant has a non-alcohol abusing parent while scores of two to five indicate potentially problem drinking not yet indicative of alcohol abuse (Pilat \& Jones, 1984). Additionally, psychometric evaluation of the CAST supports sufficient split-half reliability with a Spearman-Brown reliability coefficient of .98 and criterion-related validity with a validity coefficient of $.78(p<.0001)$

Attachment Style Questionnaire (ASQ). This 40-item measure assesses respondents' romantic attachment styles based on Hazan and Shaver's (1987) romantic attachment types (Feeney, Noller, \& Hanrahan, 1994; See Appendix C). The measure consists of five subscales: Confidence in Self and Others, Need for Approval, Preoccupation with Relationships, Discomfort with Closeness, and Relationships as Secondary. Of the five subscales, Confidence represents Hazan and Shaver's (1987) secure attachment. The other subscales assess features associated with insecure attachment. For example, Feeney et al.'s (1994) Discomfort with Closeness maps onto Hazan and Shaver's (1987) avoidant attachment because avoidant attachment is characterized as difficulty trusting and getting close to one's partner. Hazan and Shaver's (1987) anxious/ambivalent romantic attachment style is reflected in Feeney et al.'s (1994) Preoccupation with Relationships subscale.

Item responses are indicated using a six-point Likert scale with $1=$ totally disagree and $6=$ totally disagree. The five subscales are scored separately by summing item responses, some of which are reverse scored. Greater subscale scores indicate increased prominence of those attachment types (Feeney, Noller, \& Hanrahan, 1994). 
Psychometric analyses reveal strong reliability and validity. High levels of internal consistency were demonstrated with Cronbach's alpha ranging from .76 to .85 . Test-retest reliability was examined over a period of 10 weeks. Coefficients ranged from .67 to .80 between the subscales, which indicates acceptable reliability over time (Feeney et al., 1994).

Parent-Child Conflict Tactics Scale (CTSPC). The CTSPC is designed to assess non-violent discipline, psychological aggression and physical abuse in the participant's family of origin during their worst year living at home (Straus, Hamby, Finkelhor, Moore, \& Runyan, 1998; See Appendix D). It should be noted that the CTSPC is a modification of Straus's (1979) original Conflict Tactic Scale (CTS). While the CTS was originally developed to research physical abuse of spouse, it was modified to apply to child abuse (Straus \& Hamby, 1997). This modification, however, resulted in numerous limitations, which development of the CTSPC aimed to address (Straus \& Hamby, 1997).

Although the CTSPC assesses a range of abuse types, the current study is only utilizing items from the physical aggression scale. The physical aggression subscale includes items that assess a range of physical maltreatment, from no violence to very severe violence (Straus et al., 1998). The current study, however, only utilizes the eight items that measure severe and very severe physical maltreatment. Participants assessed frequency of physical abuse during their worst year at home on a seven-point scale ranging from $0=$ never to $6=$ over 20 incidents. Separate responses were given for mothers and fathers. 
Psychometric assessment reveals sound construct validity and moderate internal consistency reliability (.55) (Straus et al., 1998). Straus et al. (1998), attribute this relatively low reliability to the assumption that parents may be unlikely to engage in all types of maltreatment. Additionally, severe forms of physical abuse may be inconsistent and rare (Straus, 1998).

Psychological Maltreatment Scale (PMS). The PMS is a 7-item measure that assesses the presence of verbal abuse in the respondent's family of origin (Briere \& Runtz, 1988; See Appendix E). Using a seven-point scale, participants respond separately for each parent, and responses indicate the frequency with which abuse behaviors occurred in a year during childhood (e.g. $0=$ never, $1=$ once, $2=$ twice, $3=3-5,4=6$ $10,5=11-20,6=>20$ ). Responses for both the mother and the father are summed with higher totals indicating greater incidence of childhood verbal abuse. Psychometric assessment of the measure indicates strong internal consistency at .87 (Briere \& Runtz, 1988).

Family Adaptability and Cohesion Evaluation Scales IV (FACES IV). FACES IV is a 42-item self-report measure that seeks to assess levels of family cohesion and flexibility (Olson, 2011; See Appendix F). Cohesion is defined as "the emotional bonding that family members have toward one another" while flexibility is considered "the quality and expression of leadership and organization, role relationship, and relationship rules and negotiations" (p. 65). The measure was developed based on the Circumplex Model, which theorizes that "balanced levels of cohesions and flexibility are most conducive to healthy family functioning" (p. 65). Six subscales, three assessing cohesion and three assessing flexibility, are used to measure varying levels of each 
construct. Cohesion subscales include Enmeshed, Balanced Cohesion, and Disengaged. Flexibility subscales include Chaotic, Balanced Flexibility, and Rigid (Olson, Gorall, \& Tiesel, 2007). Responses on the FACES IV are indicated using a five point Likert-type scale, which ranges from $I=$ does not describe our family at all to $5=$ describes our family very well. Item scores within each subscale are added to determine each subscale score. High subscale scores indicate greater presence of that construct in the respondent's family (e.g., higher levels of cohesion would indicate greater presence of emotional bonding). For the purpose of this study, only the Cohesion subscales will be used in analysis.

Psychometric evaluation of FACES IV revealed that the measure and its subscales were reliable and valid (Olson, 2011; Olson et al., 2007) Olson (2011) demonstrated content validity and construct validity. A group of family therapists from the American Association of Marriage and Family Therapy (AAMFT) examined the subscales and determined that the measure's item content precisely characterize the content areas (Olson, 2011). Additionally, construct validity was determined using confirmatory factor analysis. Examining the concurrent validity between FACES IV and the Self-Report Family Inventory, Family Assessment Device, and Family Satisfaction Scale supported construct validity in two different validation studies (Olson, 2011; Olson et al., 2007). Also, Olson et al. (2007) found internal consistency reliability ranging from .77 to .89 among the subscales.

Family Satisfaction Scale (FSS). The FSS assesses participants' satisfaction with their family of origin (See Appendix G). Although the original version of the FSS contains 14-items (Olson \& Wilson, 1982), the current study utilizes the adapted 10-item 
version (Thomas \& Ozechowski, 2000). Items responses are based on a five-point Likerttype scale. Responses range from $1=$ does not describe our family at all to $5=$ describes our family very well. Items assess a number of family dynamics including closeness between members, flexibility, and conflict resolution. Item responses are added and the total score represents the respondent's level of family satisfaction, with higher scores indicating higher levels of satisfaction. With a Cronbach's alpha of .92 and test-retest reliability at .75, Thomas and Ozechowski (2000) determined the 10-item FSS to be psychometrically sound. Additionally, construct validity was established using confirmatory factor analysis.

Parental Attachment Questionnaire (PAQ). Kenny (1987) designed the PAQ to assess participant attachment to their parents based on Ainsworth et al.'s (1978) theory (See Appendix H). The questionnaire specifically assessed perceived parental availability, understanding, acceptance, respect for individuality, facilitation of independence, interest in interaction with parents and affect towards parents during visits or reunion, student help-seeking behavior in situations of stress, satisfaction with help obtained from parents, and adjustment to separation (Kenny, 1987, p. 20).

This 55-item measure has three subscales: Affective Quality of Attachments, Parental Fostering of Autonomy, and Parental Role in Providing Emotional Support (Kenny \& Donaldson, 1991). Using a five-point Likert scale, which ranged from $1=$ not at all to $5=$ very much, the measure, originally assessing parents as a unit, now asks participants to provide separate ratings for the father and mother (Kenny, Moilanen, Lomax, \& Brabeck, 1993). Item ratings are summed with higher scores indicating greater positive affective quality of attachment, perception that parents are fostering autonomy, 
and perception that parents provide emotional support when needed (Kenny \& Donaldson, 1991).

Psychometric evaluation revealed strong internal consistency and test-retest reliability (Kenny, 1987). Regarding internal consistency among males, Cronbach's alpha was .93 , and among females, it was .95 . Test-retest reliability at .92 was demonstrated over a two-week period. In exploring convergent validity, Kenny and Donaldson (1991) found moderate correlation with scales such as the Family Environment Scale (FES; Moos, 1985).

Rosenberg Self-Esteem Scale (RSE). The RSE is a 10-item measure designed to assess respondents' positive or negative attitudes toward the self (i.e., self-esteem) (Rosenberg, 1965; See Appendix I). Rosenberg (1965) characterizes high self-esteem as having self-acceptance, self-respect, and feelings of worthiness. Alternatively, individuals with low self-esteem embody "self-rejection, self-dissatisfaction, [and] self-contempt" (Rosenberg, 1965, p. 31).

Participants are asked to indicate whether they strongly agree (SA), agree (A), disagree (D), or strongly disagree (SD) with the items presented. Items include statements such as "On the whole, I am satisfied with myself" and "I feel I do not have much to be proud of" (Rosenberg, 1965, p. 17). Responses are evaluated on a four-point scale (i.e., $\mathrm{SA}=1, \mathrm{~A}=2, \mathrm{D}=3, \mathrm{SD}=4$ ) and five items are reverse scored. Item scores are summed and higher scores denote lower self-esteem (Rosenberg, 1965).

Numerous studies evaluating the RSE's psychometric properties have found both sound validity and reliability. Rosenberg $(1965,1979)$ demonstrated good construct validity. Additionally, Sinclair, Blais, Gansler, Sandberg, Bistis, and LoCicero (2010) 
established good convergent and discriminant validity. Internal consistency reliability was demonstrated with a Cronbach's alpha of .91 (Sinclair et al., 2010).

\section{Procedure}

Participants were recruited through the University's online research management system, SONA. Students completing this survey received credit toward their Introductory Psychology course. Participants completed the survey online after reading an informed consent statement, which informed them of their right to withdraw any time without penalty and their right to anonymous confidential participation (See Appendix J). Before proceeding to the questionnaire, participants were required to click the "I Consent" radial button, thus, signifying their agreement with the informed consent statement. Participants completed the survey in approximately 30 minutes. They also were provided with a printable debriefing statement upon completing the survey.

\section{Results}

\section{Data transformation}

Before conducting analyses, the following data transformations were conducted for each measure. A total score for the Children of Alcoholics Screening Test (CAST) was calculated by summing all participant responses. The Attachment Style Questionnaire (ASQ) sum scores were calculated using totals from the five subscales: Relationships as Secondary (RS), Need for Approval (NA), Discomfort with Closeness (DC), Preoccupation with Relationships (PR), and Confidence (C). Prior to summation, the Confidence subscale was reverse coded so that the ASQ sum score would accurately reflect levels of insecure attachment. 
On both the Parent-Child Conflict Tactics Scale (CTSPC) and the Psychological Maltreatment Scale (PMS) items were summed to calculate a composite score. For the Family Adaptability and Cohesion Evaluation Scales IV (FACES IV), the authors provided an Excel spreadsheet to automatically compute the raw Cohesion Dimension score. The raw scores were converted in the spreadsheet into percentile scores, which were manually entered into SPSS for analyses. The Family Satisfaction Scale (FSS) scores were calculated by summing all item responses. On the Parental Attachment Questionnaire (PAQ), three subscale scores (i.e., Affective Quality of Relationships, Parents as Facilitators of Independence, and Parents as Source of Support) were calculated and summed to create an overall PAQ score for each parent. An overall score on the Rosenberg Self-Esteem Scale (RSE) was calculated by reverse coding the necessary questions and then summing all items.

\section{Parental alcoholism and adult relationship attachment style}

The first set of analyses examined differences between the ACOA and nonACOA groups on adult relationship attachment style. It was hypothesized that a significant relationship would exist between parental alcoholism and ACOA relationship attachment style. Specifically, ACOAs would experience more insecure attachment styles in relationships than non-ACOAs. This hypothesis was supported.

To test the hypothesis, an independent samples $t$-test was conducted on adult relationship attachment style with ACOA status (ACOA, Non-ACOA) as the independent variable and ASQ sum scores as the dependent variable. Analyses revealed that ACOAs $(M=140.5 ; S D=22.0)$ experience significantly more insecurity in adult attachments than non-ACOAs $(M=126.9 ; S D=22.6), t(219)=4.53, p<.001$. Further $t$-tests examining 
the five ASQ subscales separately revealed that ACOAs were less securely attached than non-ACOAs on all subscales except "Relationships as Secondary" (see Table 3).

\section{Parental alcoholism and adult self-esteem}

In addition to examining adult relationship attachment style, the first study question also sought to explore differences in self-esteem between the ACOA and nonACOA group. Because of the limited and conflicting literature on this relationship, this question was considered exploratory. It is also important to note that a limited sample of participants $(n=177)$ completed the RSE because it was not included with the measures in Phase 1 (Konz, 2009).

To test the hypothesis, an independent samples $t$-test was conducted with ACOA status (ACOA, Non-ACOA) as the independent variable and RSE sum scores as the dependent variable. Analyses revealed that ACOAs $(M=20.1 ; S D=5.5)$ and nonACOAs $(M=18.6 ; S D=5.8)$ did not experience significant differences in self-esteem.

\section{Parental alcoholism and familial factors}

Research has conceptualized the negative impact of family dysfunction on family satisfaction, family cohesion, and parent-child attachment. Because parental alcoholism is often considered a type of family dysfunction, it was hypothesized that ACOAs would report lower levels of family satisfaction, lower levels of family cohesion, and weaker parent-child bonds than non-ACOA participants.

Four independent samples $t$-tests were conducted to examine the relationship between the independent variable, ACOA status (ACOA, non-ACOA), and the dependent variables, which were family satisfaction scale score (FSS), family cohesion score (FACES-IV), maternal parent-child attachment score (PAQ-mother), and paternal parent- 
child attachment score (PAQ-father) (see Table 4). With respect to family satisfaction, ACOAs $(M=33.0 ; S D=8.7)$ evidenced significantly less satisfaction than non-ACOAs $(M=38.3 ; S D=7.8), t(220)=-4.78, p<.001$. Additionally, the mean scores highlight that ACOAs reported low family satisfaction which non-ACOAs reported moderate family satisfaction.

ACOAs $(M=43.2 ; S D=26.5)$ also reported significantly less family cohesion than non-ACOAs $(M=56.2 ; S D=28.6), t(221)=-3.52, p=.001$. Although ACOAs reported significantly less family cohesion than non-ACOAs, both groups were still considered connected. Further, ACOAs were less securely attached to their fathers $(M=$ 181.6; $S D=42.8)$ and mothers $(M=194.4 ; S D=39.5)$ than non-ACOAs with their fathers $(M=203.4 ; S D=34.5), t(189.43)=-4.08, p<.001$, and mothers $(M=215.1 ; S D$ $=31.3), t(189.31)=-4.27, p<.001$. This second hypothesis, therefore, was fully supported.

Additionally, to further explore the dysfunction associated with parental alcoholism and these family factors, bivariate correlations were conducted between participants' CAST, FSS, FACES, PAQ-mother, and PAQ-father scores. Results indicated that all variables were significantly correlated with one another. While familial factors were positively correlated with one another, they were negatively correlated with CAST scores (see Table 5). That is, as CAST scores increased, indicating greater dysfunction, positive familial factors decreased.

\section{Parental alcoholism and abuse}

Given support for the increased likelihood of child abuse (physical, sexual, and verbal) in homes with an alcohol-abuse parent, it was hypothesized that ACOAs would 
report increased physical and verbal abuse in the family of origin than non-ACOAs. To explore this hypothesis, four independent samples $t$-tests were conducted (see Table 6) with ACOA status (ACOA, Non-ACOA) as the independent variable and physical abuse, maternal verbal abuse, paternal verbal abuse, and overall verbal abuse as the dependent variables.

Results indicated that ACOAs $(M=4.6 ; S D=13.1)$ experience significantly more instances of physical abuse than non-ACOAs $(M=1.2 ; S D=3.3), t(113.22)=2.54, p<$ .05. Further, ACOAs experienced significantly more verbally abusive behaviors from their mothers $(M=12.5 ; S D=11.4)$ and fathers $(M=10.0 ; S D=10.6)$ than non-ACOAs did from their mothers $(M=6.8 ; S D=8.0), t(180.63)=4.33, p<.001$, and fathers $(M=$ $6.3 ; S D=8.3), t(192.25)=2.90, p<.01$. A final independent samples $t$-test concluded that ACOAs $(M=22.5 ; S D=18.0)$ experience greater instances of verbal abuse overall than non-ACOAs $(M=13.0 ; S D=15.0), t(221)=4.28, p<.001$.

Additionally because verbal and physical abuse factors are typically associated with familial dysfunction, these variable scores were included in the bivariate correlation comparisons with participants' CAST, FSS, FACES, PAQ-mother, and PAQ-father scores. Results indicated that verbal and physical abuse scores were significantly correlated with all other variables (see Table 5). Specifically, physical and verbal parental abuse behaviors were positively correlated with CAST scores, indicative of increased dysfunction, and negatively correlated with all familial factors.

\section{Predictors of adult relationship attachment style}

To examine which combination of factors best predict adult relationship attachment, multiple regression analyses were conducted among ACOAs and non- 
ACOAs. Because no prior research examined these factors in combination, this research aim was exploratory. Family satisfaction, family cohesion, maternal attachment, paternal attachment, verbal abuse, and physical abuse were examined as predictors of adult relationship attachment. Among ACOAs, these factors (i.e., family satisfaction, family cohesion, maternal attachment, paternal attachment, verbal abuse, and physical abuse) accounted for $22 \%$ of the variance in adult relationship attachment $(F(6,91)=5.47, p<$ $.001)$. Less attachment with fathers and presence of verbal abuse were most predictive of insecure adult attachment among ACOAs. Among non-ACOAs, this combination of factors accounted for $23 \%$ of the variance in adult relationship attachment $(F(6,109)=$ $6.64, p<.001$ ). In contrast with ACOAs, lower family satisfaction was the strongest predictor of less insecure adult relationship attachment among non-ACOAs (see Table 7.)

\section{The role of gender}

This study also aimed to examine the relationship between ACOA gender, the gender of the substance abusing/dependent parent, adult attachment style, and the familial variables of interest. To address this aim, an initial $2 \times 3$ ANOVA was conducted to examine the interaction between ACOA gender and gender of the alcohol abusing parent (e.g., mother, father, both) and its effect on adult relationship attachment style among ACOAs. No main effects or interaction effects were significant. Additionally, a second 2x3 ANOVA was conducted with ACOA self-esteem as the dependent variable. Again, no main effects or interaction effects were significant.

Follow-up analyses were conducted to examine the impact of gender of the alcohol abusing parent and ACOA gender separately on the study variables. First, oneway ANOVAs were conducted with ACOA gender as the independent variable and 
family satisfaction, family cohesion, parent-child attachment, physical abuse, verbal abuse, adult relationship attachment, and self-esteem as the dependent variables. No results were significant.

A second set of one-way ANOVAs were conducted with parent gender (e.g., mother, father, both) as the independent variable and family satisfaction, family cohesion, parent-child attachment, physical abuse, verbal abuse, adult relationship attachment, and self-esteem as the dependent variables. Analyses revealed that for ACOAs, the sex of the substance abusing parent was significantly related to rates of physical abuse $(F(2,90)=$ $5.43, p<.01)$, verbal abuse $(F(2,90)=3.19, p<.05)$, and family satisfaction, $F(2,90)=$ $3.65, p<.05$. Specifically, results of a Tukey's HSD test indicate that ACOAs with both parents who had substance abuse/dependence reported significantly more instances of physical abuse $(M=11.4 ; S D=22.4)$ than those with either a substance abusing mother $(M=1.2 ; S D=2.4)$ or father $M=2.3 ; S D=5.9)$. Additionally, ACOAs with two substance-abusing parents experienced significantly more verbal abuse $(M=31.7 ; S D=$ 21.3) than ACOAs with a substance-abusing father $(M=20.2 ; S D=17.2)$. Finally, ACOAs with two substance-abusing parents reported lower levels of family satisfaction $(M=29.3 ; S D=9.9)$ when compared to ACOAs with a substance-abusing father $(M=$ $34.5 ; S D=8.1)$

\section{Mediating factors}

The final aim of this study was to assess whether family cohesion, family satisfaction, parent-child attachment, and verbal abuse would mediate the relationship between ACOA experience and adult relationship attachment (See Figure 1). Analyses were conducted in concordance with Baron and Kenny's (1986) article. When 
determining mediation, it is necessary that the predictor variable (i.e., ACOA status), the outcome variable (i.e., adult attachment style), and the potential mediating variables (i.e., family cohesion, family satisfaction, parent-child attachment, and verbal abuse) be significantly correlated with one another. Therefore, bivariate correlation analyses between ACOA status, adult attachment style, and each of the potential mediating variables were conducted first. It was then necessary to assess whether ACOA status and each of the potential mediating variable predicted adult attachment style. Five multiple regression analyses then were conducted with ACOA status and a familial variable as predictors and adult attachment style as the outcome. For mediation to be present, it is critical that the potential mediating variable (i.e., family cohesion, family satisfaction, parent-child attachment, and verbal abuse) significantly predict adult attachment style, while controlling for ACOA status. If full mediation is present, the influence of the predictor variable on the outcome variable is reduced and no longer significant in the regression. If partial mediation is present, the influence of the predictor variable of the outcome variable is reduced but still significant.

The test for mediation was family cohesion (See Figure 2). It was predicted that a relationship between ACOA status and adult attachment style would be mediated by family cohesion. Bivariate correlation analyses revealed that ACOA status was significantly related to adult attachment $(r=-0.29, N=221, p<.001)$ and family cohesion ( $r=0.23, N=223, p=.001)$. Similarly, family cohesion was significantly correlated with adult attachment $(r=-0.37, N=221, p<.001)$. A multiple regression analysis revealed that ACOA status significantly predicted adult attachment style, $\beta(218)$ $=-0.22, p=.001$. Finally, family cohesion significantly predicted adult attachment style 
while controlling for ACOA status, $\beta(218)=-0.32, p<.001$. Family cohesion was, therefore, identified as a partial mediator between ACOA status and adult attachment style.

Next, it was predicted that family satisfaction would mediate a relationship between ACOA status and adult attachment style (See Figure 3). Bivariate correlation analyses identified that family satisfaction was significantly related to ACOA status ( $r=$ $0.31, N=221, p<.001)$ and adult attachment style $(r=-0.49, N=221, p<.001)$. A multiple regression analysis demonstrated that ACOA status significantly predicted adult attachment style, $\beta(218)=-0.16, p<.05$. While controlling for ACOA status, family satisfaction significantly predicted adult attachment style, $\beta(218)=-0.44, p<.001$. Family satisfaction was, therefore, a partial mediator.

When examining parent-child attachment as a mediator, maternal and paternal parent-child attachment were assessed separately (See Figures 4 and 5 respectively). Regarding maternal parent-child attachment, bivariate correlations identified significant relationships between maternal parent-child attachment and ACOA status $(r=.28, N=$ $221, p<.001)$, as well as, adult attachment style $(r=-0.40, N=219, p<.001)$. In the multiple regression analysis, ACOA status significantly predicted adult attachment style, $\beta(216)=-0.19, p<.05$. Maternal parent-child attachment also significantly predicted adult attachment style while controlling for ACOA status, $\beta(216)=-0.35, p<.001$. Maternal parent-child attachment was also a partial mediator.

When examining paternal parent-child attachment, bivariate correlations revealed significant relationships between paternal parent-child attachment and both ACOA status $(r=0.27, N=217, p<.001)$ and adult attachment style $(r=-0.44, N=216, p<.001) . \mathrm{A}$ 
multiple regression analysis revealed that ACOA status significantly predicted adult attachment style, $\beta(213)=-0.17, p<.01$. When controlling for ACOA status, paternal parent-child attachment significantly predicted adult attachment style $(\beta(213)=-0.40, p$ $<.001$ ), thus identifying it too as a partial mediator.

The final variable predicted to mediate the relationship between ACOA status and adult attachment style was verbal abuse (See Figure 6). Bivariate correlation revealed that verbal abuse was significantly related to ACOA status $(r=-0.28, N=223, p<.001)$ and adult attachment style $(r=0.40, N=221, p<.001)$. The multiple regression analysis identified ACOA status as a significant predictor of adult attachment style, $\beta(218)=$ $0.20, p<.01$. Finally, when controlling for ACOA status, verbal abuse significantly predicted adult attachment style, $\beta(218)=0.35, p<.001$. Overall, given these results, family cohesion, family satisfaction, maternal parent-child attachment, paternal parentchild attachment, and verbal abuse were all identified as partial mediators of the relationship between ACOA status and adult attachment style.

\section{Discussion}

The aim of the present study was to investigate family factors that influence the relationship between parental alcoholism and ACOA outcomes. Not only does this research contribute to understanding of ACOA relationship outcomes, but it also contributes to the growing emphasis in research on the heterogeneity of ACOA outcomes. Furthermore, while the factors (i.e., family cohesion, family satisfaction, parent-child attachment, and verbal abuse), explored in this study have been examined in previous studies, they have not been examined as possible mediators of adult relationship attachment. 
The first objective of this study was to investigate the relationship between ACOA status and adult relationship attachment style to determine whether ACOAs would report greater levels of insecure relationship attachment than non-ACOAs. Previous research has evidenced conflicting outcomes regarding this variable. For example, while some studies (Jaeger et al., 2000; Kelly et al., 2005; and Vungkhanching et al., 2004) support that ACOAs are more likely to have insecure relationship attachments, Beesley and Stoltenberg (2002) found no significant attachment style differences between ACOAs and non-ACOAs.

Results from this study indicate that ACOAs experience significantly more insecurity in adult relationship attachments than non-ACOAs. ACOAs scored higher on dimensions assessing need for approval, discomfort with closeness, and preoccupation with relationships in adult relationships. A number of potential explanations exist for this finding.

The "discomfort with closeness" dimension is characterized by difficulty trusting and getting close to one's partner (Feeney et al., 1994). Bowlby (1973) theorized that infants who do not feel that their caregiver will meet their needs become anxious, fearful, and angry, thus characterizing insecure attachment. Given the lack of nurturance, positive affect, and emotional sensitivity that can characterize alcohol-abusing families (Brown, 1988; Eiden et al., 1999), it seems logical that ACOAs would have difficulty trusting and forming close attachments for fear of being rejected or neglected.

Regarding ACOAs' increased scores on the 'need for approval' and 'preoccupation with relationship' dimensions, Feeney et al. (1994) highlight their association with a lack of self-confidence. Bowlby (1973) posits that infants who 
perceive their caregiver as unavailable experience lowered self-confidence throughout infancy, early childhood, and adolescence. Additionally, Hazan and Shaver (1987) theorize that relationship expectations and attachment styles remain consistent from childhood into adulthood, thus influencing romantic relationship behavior. The resulting lowered confidence from insecure parent-child attachment, therefore translates into adult relationships. Specifically, adults with anxious-ambivalent attachment style worry that their partner doesn't love them and will leave the relationship (Hazan \& Shaver, 1987). Among ACOAs, therefore, lack of self-confidence from insecure childhood attachments may manifest as increased need for approval and preoccupation with adult relationships.

In addition to examining adult relationship attachment style, the first research question also explored differences in levels of self- esteem between ACOAs and nonACOAs. When applying Bowlby's (1973) previously stated theory that insecure parentchild attachment leads to lowered self-confidence, it would seem logical that because ACOAs have more insecure adult attachment, they would also report lower levels of selfesteem. Furthermore, a breadth of research supports a relationship between parental alcoholism and low self-esteem (Bush et al., 1995; Lease, 2002; Rangarajan, 2008; Rangarajan \& Kelly, 2006). Results in this study, however, did not indicate significant differences in self-esteem between ACOAs and non-ACOAs.

There are several possible reasons for this result. For example, in Hall's (2007) study comparing African American ACOA and non-ACOA university students, no significant differences in self-esteem were observed. It was hypothesized that this outcome might be attributed to resiliency among university students who may have experienced protective factors. While the current study sought to examine familial 
protective factors (i.e., family cohesion, family satisfaction, and parent-child attachment) among ACOAs, the factors were specifically chosen for their potential relationship with ACOA adult attachment. Future research should examine empirically supported nonfamilial factors that influence self-esteem such as body satisfaction, peer influence, and academic achievement (Dohnt \& Tiggeman, 2006; Joshi \& Srivastava, 2009).

Additionally, rather than assessing general self-regard, as is the purpose of the RSE, perhaps it would have been more beneficial to seek a measure assessing self-esteem specific to interpersonal relationships. For example, the Texas Social Behavior Inventory (Helmreich, Stapp, \& Ervin, 1974; TSBI) is a valid and reliable measure of self-esteem that focuses on confidence and competence in social situations.

The second objective of the present study was to determine if ACOAs differ from non-ACOAs regarding family cohesion, family satisfaction, and parent-child attachment. It was hypothesized that ACOAs would report less secure attachments and lower levels of family cohesion and family satisfaction than non-ACOA participants. Results indicated that ACOAs experienced less family cohesion and less family satisfaction. Additionally, ACOAs were less securely attached to both their fathers and mothers. These results suggest the possible protective contribution of these factors for individuals experiencing greater family dysfunction often associated with parental substance misuse.

Specifically regarding family cohesion, these findings are consistent with previous research outcomes (Bijttebier et al., 2006, Larson \& Reddy, 2004). In the present study, it should be noted that while ACOAs reported lower levels of family cohesion than non-ACOAs, as a group they reported, on average, "connected cohesion" indicating emotional bonds and support within the family. When attempting to explain 
this outcome, it may be beneficial to examine the measure used for family cohesion, FACES IV. The directions for the FACES IV instruct participants to "choose the best option that applies to YOUR family," and all of the questions are phrased in the present tense. For ACOA participants with parents who have received treatment and/or are in recovery, it is likely that their current perception of family cohesion may differ from their perception during childhood when their parent was actively using and/or abusing substances. Additionally, family status and the ACOA's definition of family may be impacting results. For example, cohesion levels may be starkly different for an ACOA whose biological parents are separated or divorced when no alcoholism was present in their custodial family versus an ACOA with parental alcoholism in their custodial family.

The findings with respect to family satisfaction represent an unexplored factor in ACOA research. Although Konz (2009) revealed positive correlation between family satisfaction and positive interpersonal relationships, family satisfaction previously had not been explored among ACOAs.

The third research objective was to determine if ACOAs experienced physical and verbal abuse more than non-ACOAs. More extreme/severe forms of physical abuse such as choking, scaling, and hitting with a belt were assessed. Consistent with previous research (Black et al., 1986; Kerr \& Hill, 1992; Walsh et al., 2003), ACOAs reported experiencing higher frequencies of physical abuse than non-ACOAs. Within the ACOA participant group, results revealed a disturbing difference in severity of abuse between ACOAs with one alcohol-abusing parent and ACOAs with two alcohol-abusing parents. This will be discussed in further detail under the fifth research objective. 
The next research objective sought to explore which factor or combination of factors (i.e., family cohesion, family satisfaction, parent-child attachment, verbal abuse, and physical abuse) best predict adult relationship attachment in ACOA versus nonACOA participants. Because no prior research had examined these factors in combination this objective was left exploratory. Among ACOAs, results indicated that the variables of interest accounted for $22 \%$ of variance in adult attachment with less attachment with fathers and the presence of verbal abuse being the most predictive of insecure adult attachment.

As previously noted, current research results indicate verbal abuse as the strongest predictor of ACOA relationship attachment outcomes. This outcome is consistent with previous research. For example, Roberto et al. (2009) found that college students with non-secure attachment styles described their parents at significantly more verbally abusive than participants with secure attachment styles. Additionally, Riggs \& Kaminski (2010) found that childhood emotional abuse predicted insecure adult attachment among college students. While verbal abuse has received considerably less focus in research compared to physical and sexual abuse, this study's finding necessitates further exploration of the impact of verbal abuse among ACOAs. Additionally, this result furthers understanding of heterogeneity among ACOAs as verbal abuse was more predictive of relationship outcomes than physical abuse. Although this result does not minimize the importance of exploring physical abuse, it does emphasize the significant detrimental impact of verbal abuse.

Interestingly, attachment with fathers was the second strongest predictor of insecure adult attachment. While Bowlby's (1973) theory conceptualizes the primary 
attachment figure as someone who was readily available to the infant, this person was most frequently the infant's mother. Despite the modern reality of dual income households, numerous studies continue to support that mothers assume the most responsibility in childcare (Cabrera, Tamis-LeMonda, Bradley, Hofferth, \& Lamb, 2000; Jacobs and Kelley, 2006; Kelley, Braitman, Henson, Schroeder, Ladge, and Gumienny, 2010). It is perplexing, therefore, that attachment with fathers was a stronger predictor of adult attachment than attachment with mothers. This finding not only highlights an avenue for continued research, but it also underscores the influential role of paternal attachment in child development.

The fifth objective in this study was to examine the relationship between ACOA gender, the gender of the substance using parent, adult attachment style, and the familial variables of interest. When examining the interaction between ACOA gender and the gender of the alcohol-abusing parent and its effect on adult relationship attachment style, no significant interaction was found. Although research examining this interaction dynamic is sparse, Kearns-Bodkin and Leonard (2008) hypothesized that relationship behaviors are modeled after interactions with the opposite gender parent and found that participants' assessment of their marital relationship was related to alcoholism in the opposite gender parent. The present study may be limited because it did not explicitly assess romantic dating relationships. The ASQ, which was used to measure adult relationship attachment style, asks generally about relationships not, necessarily romantic relationships. Perhaps this consideration would be useful to incorporate in further research of gender influences. Additionally, among ACOAs frequencies of the alcoholabusing parent were disproportionate, which may be impacting results. 
Another facet of this objective sought to explore differences in adult relationship attachment style among male and female ACOAs. Although data analysis did not reveal significant gender differences, the current study contributes to the limited amount of research examining differences among male and female ACOAs. As previously noted, female ACOA samples seem disproportionately represented in the literature, and no known research has previously examined ACOA gender differences in adult attachment style. Similarly, although no adult attachment style differences were found among those ACOAs with a mother abusing alcohol, father-abusing alcohol, or both, no previous studies were identified that aimed to evaluate these differences among ACOAs.

Additionally, the relationship between parental gender and family variables (i.e., family cohesion, family satisfaction, parent-child attachment, verbal abuse, and physical abuse) was examined among ACOAs. Results indicated that having two substanceabusing parents rather than only a substance-abusing father or a substance-abusing mother was related to significantly greater levels of physical abuse. Similarly, having two substance-abusing parents rather than a substance-abusing father was related to increased levels of verbal abuse. Additionally, ACOAs with two substance-abusing parents reported lower levels of family satisfaction when compared to ACOAs with only a substance-abusing father. These results suggest that having a sober parent may serve to protect the child from physical abuse. It is also interesting to note that with regard to verbal abuse and family satisfaction, no significant differences were found among ACOAs with two substance-abusing parents when compared to those with substanceabusing mothers. These findings underscore the potential influence of mothers in shaping 
family satisfaction. Additionally, it raises questions about potential gender differences in propensity toward certain types of abuse.

In future research on parent gender, it may be useful to examine parental marital status and onset of substance use. For example, do children with two divorced parents with substance use problems exhibit similar outcomes as children with two married parents? Exploring such marital dynamics may also necessitate identification of the custodial parent among divorced, separated, and unmarried parents. Such research aims would contribute further literature regarding differential outcomes among ACOAs.

The final research objective examined family cohesion, family satisfaction, maternal parent-child attachment, paternal parent-child attachment, and verbal abuse as mediators in the relationship between ACOA status and adult attachment style (see Figure 1). Results identified all of these variables as partial mediators between ACOA status and adult attachment. While family cohesion had been identified as a mediator between ACOA experience and adult outcomes (Roosa et al., 1996), the remaining factors had not been explored.

Given these results, presence of family cohesion, family satisfaction, and parentchild attachment serve as protective factors among ACOAs that promote healthier adult adjustment. Regarding verbal abuse, results support that while parental alcoholism uniquely contributes to family dysfunction beyond the dysfunction associated with verbal abuse, verbal abuse substantially influences ACOA adult relationship attachments. Without the presence of these protective family factors, children growing up in a home with parental alcoholism may experience emotional neglect and abuse, physical abuse dissatisfying family relationships, and poor parent-child attachment, which leads to 
maladaptive outcomes for offspring. Alternatively, emotional support, parent and family bonding, and satisfaction with family relationships can buffer the dysfunction associated with parental alcoholism and promote healthy long-term adjustment among ACOAs. These findings have substantial implications in the discussion of differential outcomes and clinical interventions among ACOAs.

\section{Clinical implications}

The results from this study have several clinical implications. Since ACOA status was related to more insecurity in adult relationships, it may be beneficial for clinicians to explore positive interpersonal behaviors. For example, clinicians might explore cognitions, emotions, and behaviors regarding need for approval, trust, and comfort with emotional vulnerability, which are relationship characteristics of insecure attachment.

The study also highlights the importance of family cohesion, family satisfaction, and parent-child attachment as protective factors among ACOAs. These protective factors are developed with emotional support and communication, bonded parent-child relationships, positive and satisfying interactions among all family members. To help foster these protective influences, it is critical for clinicians to learn about, explore, and help develop the specific characteristics of these protective constructs.

For example, since family cohesion, parent-child attachment, and family satisfaction mediate the relationship between alcoholism and adult attachment, parent training may focus on fostering a family environment that enhances the presence of these variables, therefore, decreasing the negative impact of parental alcholism on the children. Within families, focus could be placed on enhancing emotional communication and increasing bonding opportunities. Given the relationship between substance misuse and 
physical/emotional abuse, for clinicians working with a substance-abusing parent and their partner, it may be critical to explore abuse prevention techniques and resources. For instance, clinicians can connect partners to crisis resources, explore coping techniques for stress, and practice anger management.

\section{Limitations and suggestions for future research}

Although the data did support the majority of the hypotheses, the results should be interpreted with an understanding of the potential limitations associated with this study. Additionally, the findings from this study have implications for future research to better understand ACOA experiences and outcomes. For example, while the results of this study are applicable to university-aged ACOAs, they may not be useful regarding the general population because the participant sample was not diverse with respect to age and ethnicity. Future studies might explore a more diverse age range to examine outcome differences as the ACOA establishes independence in adulthood away from the family of origin. Additionally, this study did not address sexual orientation, and in future studies, it could be beneficial to explore different types of adult romantic and peer relationships. Furthermore, while female and male non-ACOAs and female ACOAs were equally represented in the data, male ACOAs were not despite efforts to exclusively recruit for ACOA males. Additionally, because this study relies on self-report data and some retrospective report, responses may be inaccurately reported. Because this study addresses sensitive topics such as parental substance use and abuse, participants may be reluctant to fully disclose or wish to conform to conventions of social desirability. Corroboration with family would be especially beneficial when reporting pattern and 
timeline parental substance use, substance use treatment, and family composition (e.g., marital status, caregivers in the home, custodial parent, etc.)

Furthermore, to better explore heterogeneity among ACOAs, future studies should examine factors such as parental marital status, alcohol use of the custodial parent, age of the child at the onset of parental substance misuse, and duration of parental substance misuse. Regarding age of the child at the onset of parent substance misuse, it is necessary to consider that the level of dysfuction within the family could change throughout a child's development depending on the timeline of parental substance use. To elaborate, as previously noted from Bowlby's (1973) theory, the primary caregiver influences parent-child attachment in infancy. It is likely, therefore, that if a parent did not engage in substance misuse until the child was older, a secure attachment free of substance associated neglect could have been formed. Assessing this factor, however, could be problematic given the reliance on retrospective memory, which may be skewed, or the child may not have been aware when parental substance misuse began. In this situation, family corroboration would be beneficial.

Additionally, if the substance using parent underwent treatment, it would be beneficial to assess the age of the child when the parent entered into treatment. Furthermore, gaining more information regarding parental marital status and alcohol status of the custodial parent allows for better conceptualization of the home environment. For example, an ACOA whose custodial parent was substance-abusing is liekly to have different familial experiences from an ACOA who did not reside with their substance-abusing parent. 
In addition to exploring the physical and verbal abuse inflicted upon ACOAs, it may be beneficial to also assess the impact of witnessing spousal or partner abuse. Goddard and Bedi (2010) posit that witnessing spousal abuse may in itself be a form of abuse given the relationship between partner abuse and maladaptive psychosocial and psychological outcomes that children develop. Because research has supported that ACOAs witness parental spousal abuse more frequently than non-ACOAs, it may be important to examine this factor in future analyses (Johnson, 2001; Nicholas \& Rasmussen, 2006).

\section{Conclusion}

Based on this study and previous research, it is evident that parental alcoholism substantially impacts the family. The results of the current study highlight the increased likelihood of insecure adult relationship attachment among ACOAs. Additionally, results indicate the increased likelihood of verbal abuse and physical abuse in families with parental alcoholism. While this study acknowledges and supports the maladaptive impact of parental alcoholism, it underscores the protective influence of key familial factors such as family cohesion, family satisfaction, and parent-child attachment. These protective factors buffer the potential negative impact of parental alcoholism and promote positive ACOA outcomes. Despite experiencing parental alcoholism, children from families who establish close satisfying bonds and are emotionally supportive and communicative can experience positive long-term adjustment. Not only does this research contribute to a growing field of research, it provides practical, applicable, and hopeful information for clinicians working with families or individuals affected by substance abuse. 


\section{References}

Ainsworth, M. D. S., Blehar, M. C., Waters, E., \& Wall, S. (1978). Patters of attachment: A psychological study of the strange situation. Hillsdale, NJ: Erlbaum.

Baron, R. M., \& Kenny, D. A. (1986). The moderator-mediator variable distinction in social psychological research: Conceptual, strategic, and statistical considerations. Journal of Personality and Social Psychology, 5l(6), 1173-1182.

Barraca, J., Yarto, L., \& Olea, J. (2000). Psychometric properties of a new family life satisfaction scale. European Journal of Psychological Assessment, 16(2), 98-106.

Beesley, D., \& Stoltenberg, C. (2002). Control, attachment style, and relationship satisfaction among adult children of alcoholics. Journal of Mental Health Counseling, 24(4), 281-298.

Bidaut-Russell, M., Smith, E. M., \& Bradford, S. E. (1994). Gender differences in lifetime psychiatric disorders between sons and daughters of alcoholic mothers: A pilot study. Alcoholism: Clinical and Experimental Research, 18(2), 244-247.

Bijttebier, P., \& Goethals, E. (2006). Parental drinking as a risk factor for children's maladjustment: The mediating role of family environment. Psychology of Addictive Behaviors, 20(2), 126-130.

Bowlby, J. (1969). Attachment and loss, Vol. 1. Attachment. New York: Basic Books. Bowlby, J. (1973). Attachment and loss, Vol. 2. Separation: Anxiety and anger. New York: Basic Books.

Black, C., Bucky, S., \& Wilder-Padilla, S. (1986). The interpersonal and emotional consequences of being an adult child of an alcoholic. International Journal of the Addictions, 21(2), 213-231. 
Brennan, K. A., Shaver, P. R., \& Tobey, A. E. (1991). Attachment styles, gender and parental problem drinking. Journal of Social and Personal Relationships, 8(4), 451-466.

Briere, J., \& Runtz, M. (1988). Multivariate correlates of childhood psychological and physical maltreatment among university women. Child Abuse \& Neglect, 12(3), 331-341.

Briere, J., \& Runtz, M. (1990). Differential adult symptomatology associated with three types of child abuse histories. Child Abuse \& Neglect, 14(3), 357-364.

Brown, S. (1988). Treating adult children of alcoholics: A developmental perspective. Oxford England: John Wiley \& Sons.

Bush, S. I., Ballard, M. E., \& Fremouw, W. (1995). Attributional style, depressive features, and self-esteem: Adult children of alcoholic and nonalcoholic parents. Journal of Youth and Adolescence, 24(2), 177-185.

Cabrera, N. J., Tamis-LeMonda, C. S., Bradley, R. H., Hofferth, S., \& Lamb, M. E. (2000). Fatherhood in the twenty-first century. Child Development, 71(1), 127136.

Carver, M., \& Jones, W. (1992). THE FAMILY SATISFACTION SCALE. Social Behavior \& Personality: An International Journal, 20(2), 71-84.

Cavell, T. A., Jones, D., Runyan, R., Constantin-Page, L. P., \& Velasquez, J. M. (1993). Perceptions of attachment and the adjustment of adolescents with alcoholic fathers. Journal of Family Psychology, 7(2), 204-212. 
Coe, M. T., Dalenberg, C. J., Aransky, K. M., \& Reto, C. S. (1995). Adult attachment style, reported childhood violence history and types of dissociative experiences. Dissociation: Progress in the Dissociative Disorders, 8(3), 142-154.

Coleman, P. K. (2003). Perceptions of Parent-Child Attachment, Social Self-Efficacy, and Peer Relationships in Middle Childhood. Infant and Child Development, 12(4), 351-368.

Corte, C., \& Becherer, M. (2007). Differential effects of maternal and paternal alcoholism and gender on drinking, alcohol-related self-cognition, and psychopathology. Journal of Addictions Nursing, 18(4), 175-185.

Dohnt, H., \& Tiggemann, M. (2006). The contribution of peer and media influences to the development of body satisfaction and self-esteem in young girls: A prospective study. Developmental Psychology, 42(5), 929-936. doi:10.1037/00121649.42.5.929

Downs, W. R., \& Miller, B. A. (1998). Relationships between experiences of parental violence during childhood and women's self-esteem. Violence and Victims, 13(1), $63-77$

Egeland, B. (2009). Taking stock: Childhood emotional maltreatment and developmental psychopathology. Child Abuse \& Neglect, 33(1), 22-26.

Eiden, R., Chavez, F., \& Leonard, K. (1999). Parent-infant interactions among families with alcoholic fathers. Development and Psychopathology, 11(4), 745-762. doi:10.1017/S0954579499002308.

Eiden, R., \& Leonard, K. E. (1996). Paternal alcohol use and the mother-infant relationship. Development and Psychopathology, 8(2), 307-323. 
Eiden, R., Edwards, E., \& Leonard, K. E. (2002). Mother-infant and father-infant attachment among alcoholic families. Development and Psychopathology, 14(2), 253-278.

El-Sheikh, M., \& Buckhalt, J. (2003). Parental Problem Drinking and Children's Adjustment: Attachment and Family Functioning as Moderators and Mediators of Risk. Journal of Family Psychology, 17(4), 510-520.

Feeney, J. A., Noller, P., \& Hanrahan, M. (1994). Assessing adult attachment. In M. B. Sperling, W. H. Berman, M. B. Sperling, W. H. Berman (Eds.), Attachment in adults: Clinical and developmental perspectives (pp. 128-152). New York, NY US: Guilford Press.

Finzi, R., Ram, A., Har-Even, D., Shnit, D., \& Weizman, A. (2001). Attachment styles and aggression in physically abused and neglected children. Journal of Youth and Adolescence, 30(6), 769-786. doi:10.1023/A:1012237813771

Fisher, G. L., Jenkins, S. J., Harrison, T. C., \& Jesch, K. (1993). Personality characteristics of adult children of alcoholics, other adults from dysfunctional families, and adults from nondysfunctional families. International Journal of the Addictions, 28(5), 477-485.

Fraley, R., \& Shaver, P. (2000). Adult romantic attachment: Theoretical developments, emerging controversies, and unanswered questions. Review of General Psychology, 4(2), 132-154. doi:10.1037/1089-2680.4.2.132.

Furtado, E. F., Laucht, M. M., \& Schmidt, M. H. (2006). Gender-related pathways for behavior problems in the offspring of alcoholic fathers. Brazilian Journal of Medical and Biological Research, 39(5), 659-669. 
Grant, B., Dawson, D., Stinson, F., Chou, S., Dufour, M., \& Pickering, R. (2006). The 12-month prevalence and trends in DSM-IV alcohol abuse and dependence: United States, 1991-1992 and 2001-2002. Alcohol Research \& Health, 29(2), 7991.

Goddard, C., \& Bedi, G. (2010). Intimate partner violence and child abuse: A childcentered perspective. Child Abuse Review, 19(1), 5-20.

Geuzaine, C., Debry, M., \& Liesens, V. (2000). Separation from parents in late adolescence: The same for boys and girls?. Journal of Youth and Adolescence, 29(1), 79-91.

Hall, J. (2007). An exploratory study of the role of kinship ties in promoting resilience among African American adult children of alcoholics. Journal of Human Behavior in the Social Environment, 15(2-3), 61-78.

Harter, S., \& Taylor, T. (2000). Parental alcoholism, child abuse, and adult adjustment. Journal of Substance Abuse, 11(1), 31-44. doi:10.1016/S0899-3289(99)00018-8.

Harrington, C. M., \& Metzler, A. E. (1997). Are adult children of dysfunctional families with alcoholism different from adult children of dysfunctional families without alcoholism? A look at committed, intimate relationships. Journal of Counseling Psychology, 44(1), 102-107.

Harris, M. S. (2008). Alcohol, child maltreatment, and parenting stress in the lives of birth mothers. Journal of Human Behavior in the Social Environment, 18(2), 129150. 
Hazan, C., \& Shaver, P. (1987). Romantic love conceptualized as an attachment process. Journal of Personality and Social Psychology, 52(3), 511-524. doi:10.1037/00223514.52.3.511.

Helmreich, R., Stapp, J., \& Ervin, C. (1974). The Texas Social Behavior Inventory (TSBI): An objective measure of self-esteem or social competence. Catalog of Selected Documents in Psychology, 4(79), MS 681.

Hetherington, E. (1972). Effects of father absence on personality development in adolescent daughters. Developmental Psychology, 7(3), 313-326.

Heyman, R., \& Slep, A. (2006). Creating and field-testing diagnostic criteria for partner and child maltreatment. Journal of Family Psychology, 20(3), 397-408. doi:10.1037/0893-3200.20.3.397.

Hussong, A., Bauer, D., Huang, W., Chassin, L., Sher, K., \& Zucker, R. (2008). Characterizing the life stressors of children of alcoholic parents. Journal of Family Psychology, 22(6), 819-832. doi:10.1037/a0013704.

Infante, D., \& Wigley, C. (1986). Verbal aggressiveness: An interpersonal model and measure. Communication Monographs, 53(1), 61-69.

Jacobs, J. N., \& Kelley, M. L. (2006). Predictors of Paternal Involvement in Childcare in Dual-Earner Families with Young Children. Fathering, 4(1), 23-47.

Jaeger, E., Hahn, N., \& Weinraub, M. (2000). Attachment in adult daughters of alcoholic fathers. Addiction, 95(2), 267-276. doi:10.1046/j.1360-0443.2000.95226713.x.

Johnson, P. (2001). Dimensions of functioning in alcoholic and nonalcoholic families. Journal of Mental Health Counseling, 23(2), 127-136. 
Jones, J. (1983). The Children of Alcoholics Screening Test: A validity study. Bulletin of the Society of Psychologists in Addictive Behaviors, 2(3), 155-163.

Joshi, S., \& Srivastava, R. (2009). Self-esteem and academic achievement. Social Science International, 25(1), 75-87.

Kearns-Bodkin, J., \& Leonard, K. (2008). Relationship functioning among adult children of alcoholics. Journal of Studies on Alcohol and Drugs, 69(6), 941-950.

Kelley, M. L., Braitmen, A., Henson, J. M., Schroeder, V., Ladge, J., \& Gumienny, L. (2010). Relationships among depressive mood symptoms and parent and peer relations in collegiate children of alcoholics. American Journal of Orthopsychiatry, 80(2), 204-212.

Kelley, M., French, A., Schroeder, V., Bountress, K., Fals-Stewart, W., Steer, K., et al. (2008). Mother-daughter and father-daughter attachment of college students ACOAs. Substance Use \& Misuse, 43(11), 1559-1570. doi:10.1080/10826080802240906.

Kelley, M. L., Nair, V., Rawlings, T., Cash, T. F., Steer, K., \& Fals-Stewart, W. (2005). Retrospective reports of parenting received in their families of origin: Relationships to adult attachment in adult children of alcoholics. Addictive Behaviors, 30(8), 1479-1495.

Kennedy, J. (1999). Romantic attachment style and ego identity, attributional style, and family of origin in first-year college students. College Student Journal, 33(2), 171. Retrieved from Academic Search Premier database.

Kenny, M. E. (1987). The extent and function of parental attachment among first-year college students. Journal of Youth and Adolescence, 16(1), 17-29. 
Kenny, M. E., \& Donaldson, G. A. (1991). Contributions of parental attachment and family structure to the social and psychological functioning of first-year college students. Journal of Counseling Psychology, 38(4), 479-486.

Kenny, M. E., Moilanen, D. L., Lomax, R., \& Brabeck, M. M. (1993). Contributions of parental attachments to view of self and depressive symptoms among early adolescents. The Journal of Early Adolescence, 13(4), 408-430.

Kerr, A., \& Hill, E. (1992). An exploratory study comparing ACoAs to non-ACoAs on family of origin relationships. Australian Journal of Marriage \& Family, 13(1), 24-33.

Larson, J., \& Reedy, B. (2004). Family process as a mediator of the negative effects of parental alcoholism on young adult dating relationships. American Journal of Family Therapy, 32(4), 289-304.

Lease, S. (2002). A model of depression in adult children of alcoholics and nonalcoholics. Journal of Counseling \& Development, 80(4), 441-451.

Leeson, F., \& Nixon, R. V. (2010). Therapy for child psychological maltreatment. Clinical Psychologist, 14(2), 30-38.

Lewis Harter, S. (2000). Psychosocial adjustment of adult children of alcoholics: A review of the recent empirical literature. Clinical Psychology Review, 20(3), 311337. doi:10.1016/S0272-7358(98)00084-1.

Melchert, T. P. (2000). Clarifying the effects of parental substance abuse, child sexual abuse, and parental caregiving on adult adjustment. Professional Psychology: Research and Practice, 31(1), 64-69. 
Miller, B., Smyth, N., \& Mudar, P. (1999). Mothers' alcohol and other drug problems and their punitiveness toward their children. Journal of Studies on Alcohol, 60(5), 632-642.

Moran, P. M., Bifulco, A., Ball, C., Jacobs, C., \& Benaim, K. (2002). Exploring psychological abuse in childhood: I. Developing a new interview scale. Bulletin of the Menninger Clinic, 66(3), 213-240.

Morimoto, Y., \& Sharma, A. (2004). Long term outcomes of verbal aggression: The role of protective factors. Journal of Emotional Abuse, 4(2), 71-99.

Mussen, P., \& Rutherford, E. (1963). Parent-child relations and parental personality in relation to young children's sex-role preferences. Child Development, 34(3), 589607.

Nicholas, K., \& Rasmussen, E. (2006). Childhood Abusive and Supportive Experiences, Inter-Parental Violence, and Parental Alcohol Use: Prediction of Young Adult Depressive Symptoms and Aggression. Journal of Family Violence, 21(1), 43-61. doi:10.1007/s10896-005-9001-3.

Ney, P. (1987). Does verbal abuse leave deeper scars: A study of children and parents. The Canadian Journal of Psychiatry / La Revue canadienne de psychiatrie, 32(5), 371-378.

Olson, D. (2011). FACES IV and the Circumplex Model: Validation study. Journal of Marital and Family Therapy, 37(1), 64-80.

Olson, D. H., Gorall, D. M., \& Tiesel, J. W. (2006). FACES IV and the Circumplex Model: Validation Study. Retrieved 2011, from http://www.facesiv.com/pdf/2.development.pdf 
Pilat, J. M., \& Jones, J. W. (1984). Identification of children of alcoholics: Two empirical studies. Alcohol Health \& Research World, 9(2), 27-33, 36.

Rangarajan, S. (2008). Mediators and moderators of parental alcoholism effects on offspring self-esteem. Alcohol and Alcoholism, 43(4), 481-491. doi:10.1093/alcalc/agn034.

Rangarajan, S., \& Kelly, L. (2006). Family communication patterns, family environment, and the impact of parental alcoholism on offspring self-esteem.

Riggs, S. A., \& Kaminski, P. (2010). Childhood Emotional Abuse, Adult Attachment, and Depression as Predictors of Relational Adjustment and Psychological Aggression. Journal of Aggression, Maltreatment \& Trauma, 19(1), 75-104.

Rodriguez-Srednicki, O., \& Twaite, J. A. (2004). Understanding and reporting child abuse: Legal and psychological perspectives: Part one: physical abuse, sexual abuse, and neglect. Journal of Psychiatry \& Law, 32(3), 315-359.

Roosa, M., Dumka, L., \& Tein, J. (1996). Family characteristics as mediators of the influence of problem drinking and multiple risk status on child mental health. American Journal of Community Psychology, 24(5), 607-624.

Shaffer, A., Yates, T. M., \& Egeland, B. R. (2009). The relation of emotional maltreatment to early adolescent competence: Developmental processes in a prospective study. Child Abuse \& Neglect, 33(1), 36-44.

Sher, K. J., Walitzer, K. S., Wood, P. K., \& Brent, E. E. (1991). Characteristics of children of alcoholics: Putative risk factors, substance use and abuse, and psychopathology. Journal of Abnormal Psychology, 100(4), 427-448. 
Sheridan, M. J. (1995). A proposed intergenerational model of substance abuse, family functioning, and abuse/neglect. Child Abuse \& Neglect, 19(5), 519-530.

Sheridan, M. J., \& Green, R. G. (1993). Family dynamics and individual characteristics of adult children of alcoholics: An empirical analysis. Journal of Social Service Research, 17(1-2), 73-97.

Sinclair, S. J., Blais, M. A., Gansler, D. A., Sandberg, E., Bistis, K., \& LoCicero, A. (2010). Psychometric properties of the Rosenberg Self-Esteem Scale: Overall and across demographic groups living within the United States. Evaluation \& the Health Professions, 33(1), 56-80.

Starrels, M. E. (1994). Gender differences in parent-child relations. Journal of Family Issues, 15(1), 148-165.

Stout, M., \& Mintz, L. B. (1996). Differences among nonclinical college women with alcoholic mothers, alcoholic fathers, and nonalcoholic parents. Journal of Counseling Psychology, 43(4), 466-472.

Straus, M. A., \& Hamby, S. L. (1997). Measuring physical and psychological maltreatment of children with the Conflict Tactics Scales. In G. Kantor, J. L. Jasinski, G. Kantor, J. L. Jasinski (Eds.), Out of darkness: Contemporary perspectives on family violence (pp. 119-135).

Straus, M. A., Hamby, S. L., Finkelhor, D., Moore, D. W., \& Runyan, D. (1998). Identification of child maltreatment with the Parent-Child Conflict Tactics Scales: Development and psychometric data for a national sample of American parents. Child Abuse \& Neglect, 22(4), 249-270.

Substance Abuse and Mental Health Services Administration. (2011). Results from the 
2010 National Survey on Drug Use and Health: Summary of national findings (HHS Publication No. 11-4658) Retrieved from http://www.samhsa.gov/data/NSDUH/2k10NSDUH/2k10Results.htm

Thomas, V., \& Ozechowski, T. J. (2000). A test of the circumplex model of marital and family systems using the clinical rating scale. Journal of Marital \& Family Therapy, 26(4), 523-534.

U.S. Department of Labor (2004). Mothers in the labor force, 1955-2004. Retrieved on January 27, 2011, from: http:/www.infoplease.com/ipa/A10104670.html.

Velleman, R., Templeton, L., Reuber, D., Klein, M., \& Moesgen, D. (2008). Domestic abuse experienced by young people living in families with alcohol problems: Results from a cross-European study. Child Abuse Review, 17(6), 387-409.

Veronie, L., \& Fruehstorfer, D. B. (2001). Gender, birth order and family role identification among adult children of alcoholics. Current Psychology: A Journal for Diverse Perspectives on Diverse Psychological Issues, 20(1), 53-67.

Vogeltanz, N., Wilsnack, S., Harris, T., Wilsnack, R., Wonderlich, S., \& Kristjanson, A. (1999). Prevalence and risk factors for childhood sexual abuse in women: National survey findings. Child Abuse \& Neglect, 23(6), 579-592. doi:10.1016/S0145-2134(99)00026-5.

Vungkhanching, M., Sher, K. J., Jackson, K. M., \& Parra, G. R. (2004). Relation of attachment style to family history of alcoholism and alcohol use disorders in early adulthood. Drug and Alcohol Dependence, 75(1), 47-53.

Walsh, C., MacMillan, H., \& Jamieson, E. (2003). The relationship between parental substance abuse and child maltreatment: Findings from the Ontario Health 
Supplement. Child Abuse \& Neglect, 27(12), 1409-1425.

doi:10.1016/j.chiabu.2003.07.002.

Weber, K., \& Patterson, B. R. (1997). The Effects of Maternal Verbal Aggression on the Adult Child's Future Romantic Relationships. Communication Research Reports, $14(2), 221-30$.

Wright, M., Crawford, E., \& Del Castillo, D. (2009). Childhood emotional maltreatment and later psychological distress among college students: The mediating role of maladaptive schemas. Child Abuse \& Neglect, 33(1), 59-68.

Wright, D. M., \& Heppner, P. (1991). Coping among nonclinical college-age children of alcoholics. Journal of Counseling Psychology, 38(4), 465-472.

World Health Organization (2004). WHO Global status report on alcohol:Part II:

Country profiles. Retrieved from http://www.who.int/substance abuse/ publications/statusreportalcoholamro/en/index.html

World Health Organization. (2006). Alcohol and violence: Child maltreatment and alcohol. Retrieved from www.who.int/entity/violence_injury_prevention/ violence/world_report/factsheets/fs_child.pdf 
Table 1

Demographic Variables for ACOA and Non-ACOA Participants

\begin{tabular}{|c|c|c|c|}
\hline Variables & $\begin{array}{c}\text { Overall } \\
\text { Sample } \\
(\mathrm{n}=223) \\
\end{array}$ & $\begin{array}{c}\text { ACOA } \\
\text { Participants } \\
(n=103) \\
\end{array}$ & $\begin{array}{l}\text { Non-ACOA } \\
\text { Participants } \\
(\mathrm{n}=120)\end{array}$ \\
\hline \multicolumn{4}{|l|}{ Gender } \\
\hline Male & $103(46 \%)$ & $43(42 \%)$ & $60(50 \%)$ \\
\hline Female & $120(54 \%)$ & $60(58 \%)$ & $60(50 \%)$ \\
\hline \multicolumn{4}{|l|}{ Ethnic Background } \\
\hline Caucasian & $191(86 \%)$ & $88(85 \%)$ & $103(86 \%)$ \\
\hline African American & $21(9 \%)$ & $10(10 \%)$ & $11(9 \%)$ \\
\hline Latin American & $6(3 \%)$ & $3(3 \%)$ & $3(2 \%)$ \\
\hline Haitian American & $1(.5 \%)$ & $0(0 \%)$ & $1(1 \%)$ \\
\hline Asian & $1(.5 \%)$ & $1(1 \%)$ & $0(0 \%)$ \\
\hline Caucasian and African American & $3(1 \%)$ & $1(1 \%)$ & $2(2 \%)$ \\
\hline \multicolumn{4}{|l|}{ College Level } \\
\hline Freshman & $133(60 \%)$ & $65(63 \%)$ & $68(57 \%)$ \\
\hline Sophomore & $57(26 \%)$ & $25(24 \%)$ & $32(27 \%)$ \\
\hline Junior & $22(10 \%)$ & $8(8 \%)$ & $14(12 \%)$ \\
\hline Senior/Graduate Student & $11(5 \%)$ & $5(5 \%)$ & $6(5 \%)$ \\
\hline \multicolumn{4}{|l|}{ Family Structure } \\
\hline Intact & $122(55 \%)$ & $37(36 \%)$ & $85(71 \%)$ \\
\hline Parents Never Married & $11(5 \%)$ & $6(6 \%)$ & $5(4 \%)$ \\
\hline Parents Separated & $16(7 \%)$ & $8(8 \%)$ & $8(7 \%)$ \\
\hline
\end{tabular}




\begin{tabular}{cccc}
\hline Variables & $\begin{array}{c}\text { Overall } \\
\text { Sample } \\
(\mathrm{n}=223)\end{array}$ & $\begin{array}{c}\text { ACOA } \\
\text { Participants } \\
(\mathrm{n}=103)\end{array}$ & $\begin{array}{c}\text { Non-ACOA } \\
\text { Participants } \\
(\mathrm{n}=120)\end{array}$ \\
\hline Parents Divorced/Not Remarried & $44(20 \%)$ & $30(29 \%)$ & $14(12 \%)$ \\
Parents Remarried & $30(13 \%)$ & $22(21 \%)$ & $8(7 \%)$
\end{tabular}

Own Substance Use Concern

Concerned

Not Concerned

Participant History of Substance Treatment ${ }^{\text {a }}$

Received Treatment

No Treatment History

Participant Mental Health Treatment History ${ }^{\mathbf{a}}$

Received Treatment

No Treatment History

Parents' History of Substance Treatment ${ }^{\mathrm{a}}$

Received Treatment

No Treatment History

Maternal Mental Health Status ${ }^{\mathrm{a}}$

Mental Health Concerns

No Mental Health Concerns

Paternal Mental Health Status ${ }^{a}$

Mental Health Concerns

No Mental Health Concerns

$\begin{array}{lll}43(19 \%) & 31(30 \%) & 12(10 \%) \\ 180(81 \%) & 72(70 \%) & 108(90 \%)\end{array}$

$10(5 \%)$

$6(6 \%)$

$4(3 \%)$

$212(95 \%)$

$96(94 \%)$

$116(97 \%)$

$28(16 \%) \quad 18(21 \%) \quad 10(11 \%)$

$149(84 \%) \quad 70(79 \%) \quad 79(89 \%)$

$\begin{array}{ccc}25(11 \%) & 25(25 \%) & 0(0 \%) \\ 194(89 \%) & 74(75 \%) & 120(100 \%)\end{array}$

$\begin{array}{ccc}31(18 \%) & 23(26 \%) & 8(9 \%) \\ 145(82 \%) & 64(74 \%) & 81(91 \%)\end{array}$

$19(11 \%) \quad 16(18 \%) \quad 3(3 \%)$

$156(89 \%) \quad 71(82 \%) \quad 85(97 \%)$

Parents' Mental Health Treatment History ${ }^{\mathrm{a}}$ 


\begin{tabular}{cccc}
\hline \multicolumn{1}{c}{ Variables } & $\begin{array}{c}\text { Overall } \\
\text { Sample } \\
(\mathrm{n}=223)\end{array}$ & $\begin{array}{c}\text { ACOA } \\
\text { Participants } \\
(\mathrm{n}=103)\end{array}$ & $\begin{array}{c}\text { Non-ACOA } \\
\text { Participants } \\
(\mathrm{n}=120)\end{array}$ \\
\hline Received Treatment & $23(13 \%)$ & $15(17 \%)$ & $8(9 \%)$ \\
No Treatment History & $154(87 \%)$ & $73(83 \%)$ & $81(91 \%)$ \\
Family History of Treatment ${ }^{\mathrm{a}}$ & & & \\
Received Treatment & $19(9 \%)$ & $16(16 \%)$ & $3(3 \%)$ \\
No Treatment History & $199(91 \%)$ & $84(84 \%)$ & $115(97 \%)$ \\
\hline
\end{tabular}

Note. ${ }^{\text {a }}$ Not all participants responded to this item 
Table 2

Gender of the Substance-using Parent

\begin{tabular}{lccc}
\hline \multicolumn{1}{c}{ ACOA Parent } \\
Mother & $\begin{array}{c}\text { Male ACOAs } \\
(\mathrm{n}=36)\end{array}$ & $\begin{array}{c}\text { Female ACOAs } \\
(\mathrm{n}=57)\end{array}$ & $\begin{array}{c}\text { ACOAs Overall } \\
(\mathrm{n}=93)\end{array}$ \\
\hline Father & $10(28 \%)$ & $7(12 \%)$ & $17(18 \%)$ \\
Both & $19(53 \%)$ & $36(63 \%)$ & $55(59 \%)$ \\
& $7(19 \%)$ & $14(25 \%)$ & $21(23 \%)$
\end{tabular}

Note. ${ }^{\text {a }}$ Not all ACOA participants identified a substance-parent in the demographic questionnaire. 


\section{Table 3}

Group Differences in Adult Relationship Attachment Style

\begin{tabular}{|c|c|c|c|c|c|c|}
\hline \multirow[b]{2}{*}{ ASQ Scale } & \multicolumn{2}{|c|}{$\mathrm{ACOA}$} & \multicolumn{2}{|c|}{ Non-ACOA } & \multirow[b]{2}{*}{$\mathrm{df}$} & \multirow[b]{2}{*}{$t$} \\
\hline & $M$ & $S D$ & $M$ & $S D$ & & \\
\hline Relationship as Secondary ${ }^{b}$ & $\begin{array}{c}20.73 \\
(\mathrm{n}=102)\end{array}$ & 4.85 & $\begin{array}{c}19.68 \\
(n=120)\end{array}$ & 4.86 & 220 & 1.59 \\
\hline Need for Approval ${ }^{\mathrm{b}}$ & $\begin{array}{c}24.99 \\
(n=103)\end{array}$ & 5.27 & $\begin{array}{c}23.21 \\
(n=120)\end{array}$ & 5.41 & 221 & $2.48^{*}$ \\
\hline Discomfort with Closeness ${ }^{\mathrm{c}}$ & $\begin{array}{c}39.53 \\
(n=103)\end{array}$ & 7.91 & $\begin{array}{c}35.52 \\
(n=119)\end{array}$ & 7.56 & 220 & $3.86 * * *$ \\
\hline $\begin{array}{l}\text { Preoccupation with } \\
\text { Relationships }\end{array}$ & $\begin{array}{c}31.15 \\
(n=103)\end{array}$ & 5.80 & $\begin{array}{c}27.79 \\
(\mathrm{n}=120)\end{array}$ & 5.71 & 221 & $4.34 * * *$ \\
\hline Confidence $^{d}$ & $\begin{array}{c}23.86 \\
(n=102)\end{array}$ & 6.54 & $\begin{array}{c}20.59 \\
(n=120)\end{array}$ & 5.55 & 199.18 & $3.98 * * *$ \\
\hline ASQ Total $^{\mathrm{a}}$ & $\begin{array}{c}140.51 \\
(n=102)\end{array}$ & 21.99 & $\begin{array}{c}126.86 \\
(n=119)\end{array}$ & 22.63 & 219 & $4.53 * * *$ \\
\hline
\end{tabular}

Note. Higher scores indicate more insecure attachment styles.

${ }^{\mathrm{a}} \mathrm{ASQ}=$ Attachment Style Questionnaire. Range of possible scores is $40-240 .{ }^{\mathrm{b}}$ Range of possible scores is $7-42 .{ }^{c}$ Range of possible scores is $10-60 .{ }^{d}$ Range of possible scores is $8-48$.

${ }^{*} p<.05 . * * * p<.001$ 
Table 4

Group Differences in Familial Factors

\begin{tabular}{|c|c|c|c|c|c|c|}
\hline \multirow[b]{2}{*}{ Familial Factors } & \multicolumn{2}{|c|}{$\mathrm{ACOA}$} & \multicolumn{2}{|c|}{ Non-ACOA } & \multirow[b]{2}{*}{$\mathrm{df}$} & \multirow[b]{2}{*}{$t$} \\
\hline & $M$ & $S D$ & $M$ & $S D$ & & \\
\hline Family Satisfaction ${ }^{a}$ & $\begin{array}{c}33.03 \\
(n=103)\end{array}$ & 8.71 & $\begin{array}{c}38.34 \\
(n=119)\end{array}$ & 7.84 & 220 & $-4.78 * * *$ \\
\hline Family Cohesion ${ }^{b}$ & $\begin{array}{c}43.17 \\
(n=103)\end{array}$ & 26.48 & $\begin{array}{c}56.23 \\
(n=120)\end{array}$ & 28.59 & 221 & $-3.52 * *$ \\
\hline \multicolumn{7}{|l|}{ Parental Attachment } \\
\hline With Mother ${ }^{\mathrm{c}}$ & $\begin{array}{c}194.38 \\
(n=101)\end{array}$ & 39.48 & $\begin{array}{c}215.14 \\
(n=120)\end{array}$ & 31.31 & 189.31 & $-4.27 * * *$ \\
\hline With Father ${ }^{c}$ & $\begin{array}{c}181.64 \\
(n=100)\end{array}$ & 42.82 & $\begin{array}{c}203.43 \\
(\mathrm{n}=117)\end{array}$ & 34.47 & 189.43 & $-4.08 * * *$ \\
\hline
\end{tabular}

Note. On all scales, higher scores indicate more of that attribute.

${ }^{a}$ Range of possible scores is $10-50 .{ }^{b}$ Range of possible scores is $10-99 .{ }^{c}$ Range of possible scores is $55-275$.

${ }^{* *} p<.01 .{ }^{* * *} p<.001$ 
Table 5

Intercorrelations for $C A S T^{a}, F S S^{b}, F A C E S I V^{c}, P A Q^{d}, P M S^{e}$, and CTSPC

\begin{tabular}{|c|c|c|c|c|c|c|c|}
\hline Measure & 1 & 2 & 3 & 4 & 5 & 6 & 7 \\
\hline 1. CAST & -- & $\begin{array}{l}-.32 * * * \\
(\mathrm{n}=221)\end{array}$ & $\begin{array}{l}-.22 * * * \\
(\mathrm{n}=222)\end{array}$ & $\begin{array}{l}-.304 * * * \\
(\mathrm{n}=220)\end{array}$ & $\begin{array}{l}-.29 * * * \\
(\mathrm{n}=216)\end{array}$ & $\begin{array}{c}.35 * * * \\
(\mathrm{n}=222)\end{array}$ & $\begin{array}{c}.32 * * * \\
(\mathrm{n}=221)\end{array}$ \\
\hline 2. FSS & -- & -- & $\begin{array}{c}.59 * * * \\
(\mathrm{n}=222)\end{array}$ & $\begin{array}{c}.61 * * * \\
(\mathrm{n}=220)\end{array}$ & $\begin{array}{c}.52 * * * \\
(\mathrm{n}=217)\end{array}$ & $\begin{array}{l}-.53 * * * \\
(\mathrm{n}=222)\end{array}$ & $\begin{array}{l}-.24 * * * \\
(\mathrm{n}=221)\end{array}$ \\
\hline $\begin{array}{l}\text { 3. FACES } \\
\text { IV }\end{array}$ & -- & -- & -- & $\begin{array}{c}.50 * * * \\
(\mathrm{n}=221)\end{array}$ & $\begin{array}{c}.47 * * * \\
(\mathrm{n}=217)\end{array}$ & $\begin{array}{l}-.28 * * * \\
(\mathrm{n}=223)\end{array}$ & $\begin{array}{c}-.20 * * \\
(n=222)\end{array}$ \\
\hline $\begin{array}{l}\text { 4. PAQ with } \\
\text { mother }\end{array}$ & - & -- & -- & -- & $\begin{array}{c}.40^{* * * *} \\
(\mathrm{n}=216)\end{array}$ & $\begin{array}{l}-.47 * * * \\
(\mathrm{n}=221)\end{array}$ & $\begin{array}{l}-.27 * * * \\
(\mathrm{n}=220)\end{array}$ \\
\hline $\begin{array}{l}\text { 5. PAQ with } \\
\text { father }\end{array}$ & -- & -- & -- & -. & - & $\begin{array}{l}-.43 * * * \\
(\mathrm{n}=217)\end{array}$ & $\begin{array}{l}-.25 * * * \\
(\mathrm{n}=216)\end{array}$ \\
\hline 6. PMS & -- & -- & -- & -- & -- & -- & $\begin{array}{c}.36^{* * *} \\
(\mathrm{n}=222)\end{array}$ \\
\hline 7. CTSPC & -- & -- & -- & - & -- & -- & -- \\
\hline
\end{tabular}

Note. On all measures the higher the score, the greater the attribution.

${ }^{a} \mathrm{CAST}=$ Children of Alcoholic Screening Test. ${ }^{\mathrm{b}} \mathrm{FSS}=$ Family Satisfaction Scale. ${ }^{\mathrm{c}}$ Faces

$=$ Family Adaptability and Cohesion Evaluation Scales IV. ${ }^{\mathrm{d}} \mathrm{PAQ}=$ Parental Attachment

Questionnaire. ${ }^{\mathrm{e}} \mathrm{PMS}=$ Psychological Maltreatment Scale. ${ }^{\mathrm{f}} \mathrm{CTSPC}=$ Parent- Child

Conflict Tactics Scale.

${ }^{* *} p<.01 .{ }^{* * *} p<.001$. 
Table 6

Group Differences in Parental Abuse Behaviors

\begin{tabular}{lcccccc}
\hline & \multicolumn{2}{c}{ ACOA } & \multicolumn{2}{c}{ Non-ACOA } & & \\
\cline { 2 - 5 } Variables & $M$ & $S D$ & $M$ & $S D$ & $\mathrm{df}$ & $t$ \\
\hline CTSPC $^{\mathrm{a}}$ & $\begin{array}{c}4.59 \\
(\mathrm{n}=103)\end{array}$ & 13.12 & $\begin{array}{c}1.22 \\
(\mathrm{n}=119)\end{array}$ & 3.31 & 113.22 & $2.54^{*}$
\end{tabular}

PMS

$\begin{array}{lcccccc}\text { Mother }^{\mathrm{b}} & \begin{array}{c}12.51 \\ (\mathrm{n}=103)\end{array} & 11.21 & \begin{array}{c}6.78 \\ (\mathrm{n}=120)\end{array} & 7.97 & 180.63 & 4.33^{* * *} \\ \text { Father }^{\mathrm{b}} & \begin{array}{c}9.98 \\ (\mathrm{n}=103)\end{array} & 10.57 & \begin{array}{c}6.25 \\ (\mathrm{n}=120)\end{array} & 8.30 & 192.25 & 2.90^{* *} \\ & & & & & \\ \text { Combined }^{\mathrm{c}} & \begin{array}{c}22.50 \\ (\mathrm{n}=103)\end{array} & 17.97 & \begin{array}{c}13.03 \\ (\mathrm{n}=120)\end{array} & 15.03 & 221 & 4.28 * * *\end{array}$

Note. On all scales, higher scores indicate greater frequency of abuse in an average year at home.

${ }^{\mathrm{a}} \mathrm{Range}$ of possible scores is $0-200 .{ }^{\mathrm{b}} \mathrm{Range}$ of possible scores is $0-42 .{ }^{\mathrm{c}} \mathrm{R}$ ange of possible scores is $0-84$.

${ }^{*} p<.05 .{ }^{* *} p<.01 .{ }^{* * *} p<.001$ 
Table 7

Predictors of Adult Relationship Attachment Style

\begin{tabular}{|c|c|c|c|c|}
\hline \multirow[b]{2}{*}{ Predictor Variables } & \multicolumn{2}{|c|}{$\mathrm{ACOA}$} & \multicolumn{2}{|c|}{ Non-ACOA } \\
\hline & $\beta$ & $t$ & $\beta$ & $t$ \\
\hline Constant & & $10.03^{* * *}$ & & $11.82^{* * *}$ \\
\hline $\mathrm{FSS}^{\mathrm{a}}$ & -.06 & -.44 & -.33 & $-2.94^{* *}$ \\
\hline $\mathrm{FACES}^{\mathrm{b}}$ & -.02 & -.14 & -.06 & -.60 \\
\hline \multicolumn{5}{|l|}{$\mathrm{PAQ}^{\mathrm{c}}$} \\
\hline With Mother & -.10 & -.86 & -.08 & -.75 \\
\hline With Father & -.25 & $-2.28^{*}$ & -.14 & -1.37 \\
\hline $\mathrm{PMS}^{\mathrm{d}}$ & .24 & $2.03^{*}$ & .01 & .13 \\
\hline CTSPC $^{\mathrm{e}}$ & -.02 & -.18 & .05 & .55 \\
\hline Adjusted $R^{2}$ & .22 & & .23 & \\
\hline$F$ & $5.47^{* * *}$ & & $6.64^{* * *}$ & \\
\hline
\end{tabular}

Note. $N=116$.

${ }^{a}$ FSS $=$ Family Satisfaction Scale. ${ }^{b}$ FACES $=$ Family Adaptability and Cohesion

Evaluation Scales IV. ${ }^{\mathrm{c}} \mathrm{PAQ}=$ Parental Attachment Questionnaire. ${ }^{\mathrm{d}} \mathrm{PMS}=$ Psychological Maltreatment Scale. ${ }^{\mathrm{e}} \mathrm{CTSPC}=$ Parent- Child Conflict Tactics Scale

${ }^{*} p<.05 .{ }^{* *} p<.01 .^{* * *} p<.001$ 


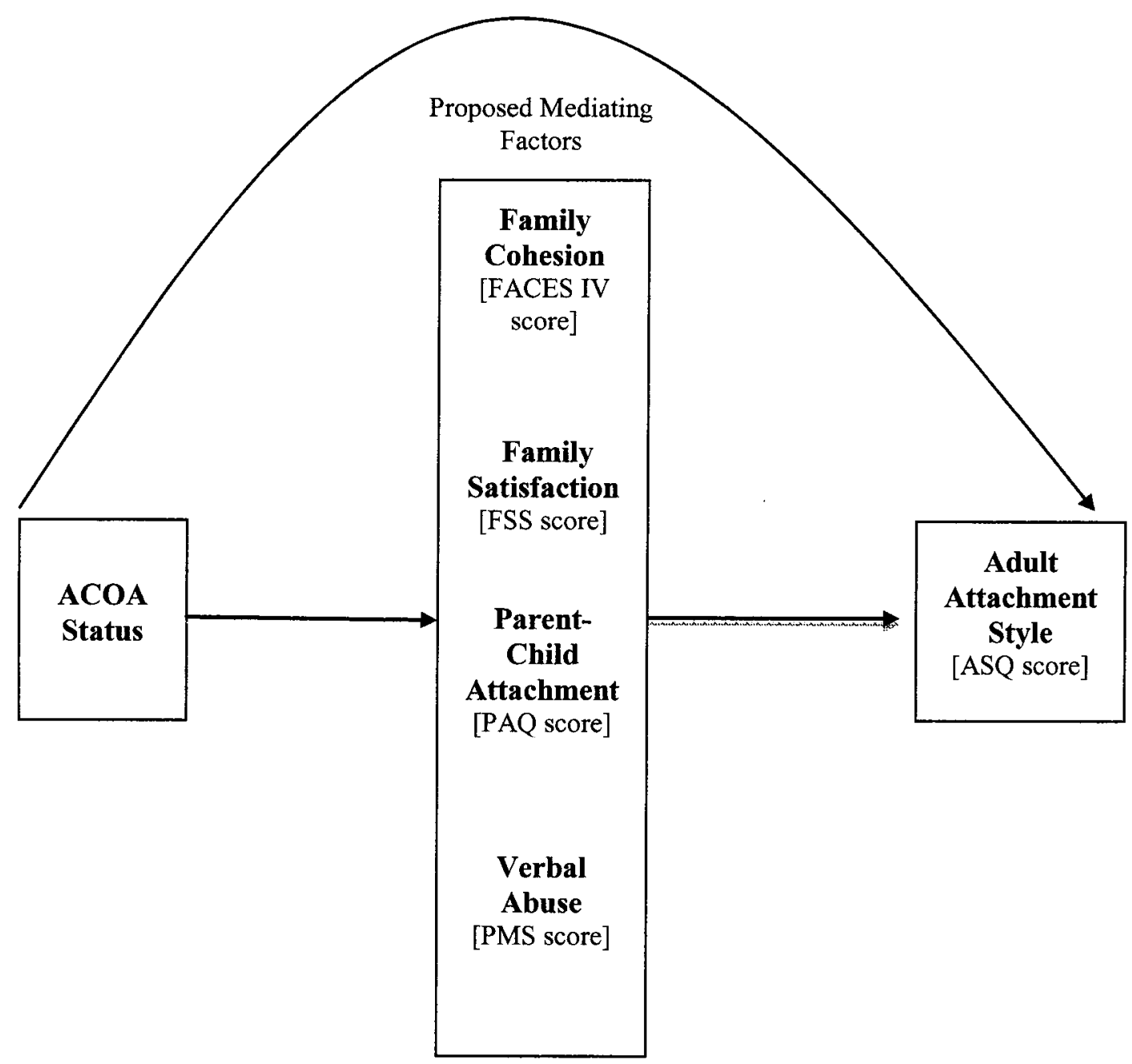

Figure 1. Hypothesized mediated model between ACOA status and adult attachment style, as potentially mediated by family cohesion, family satisfaction, parent-child attachment, and verbal abuse. 


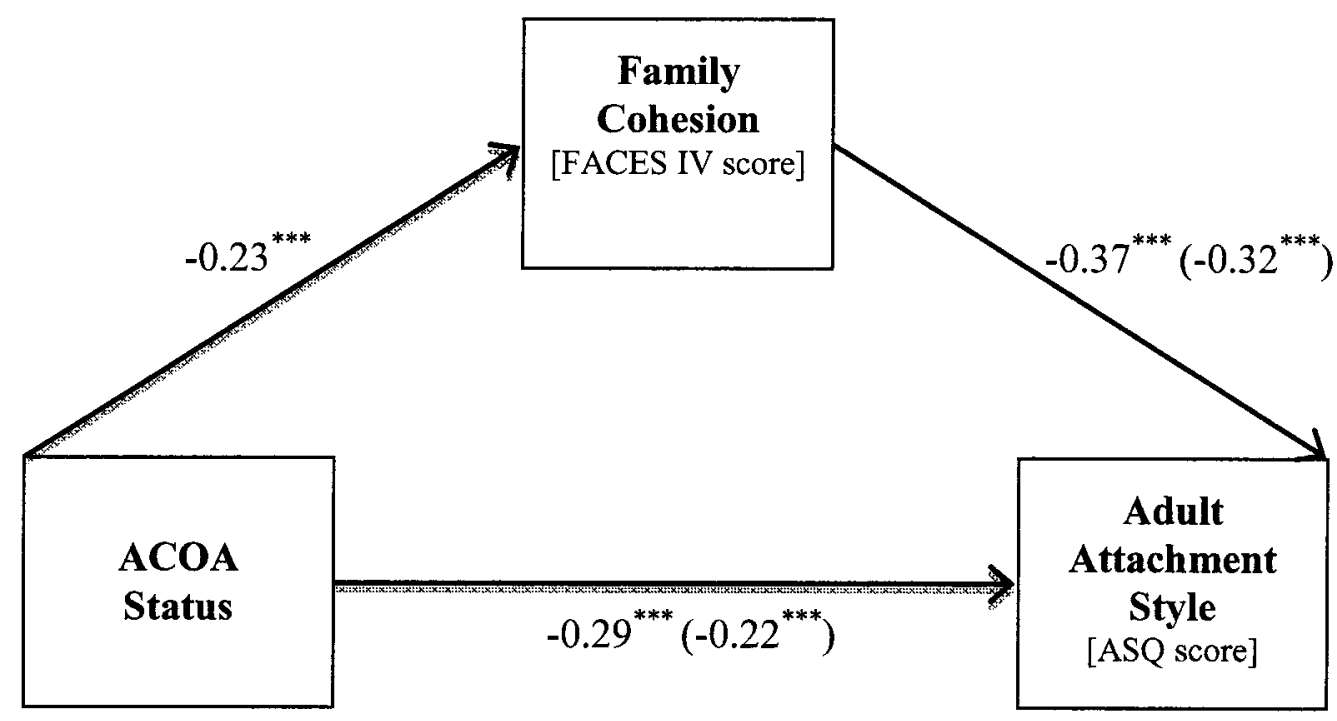

Figure 2. Hypothesized mediated model between ACOA status and adult attachment style, as partially mediated by family cohesion.

$* * * p \leq .001$ 


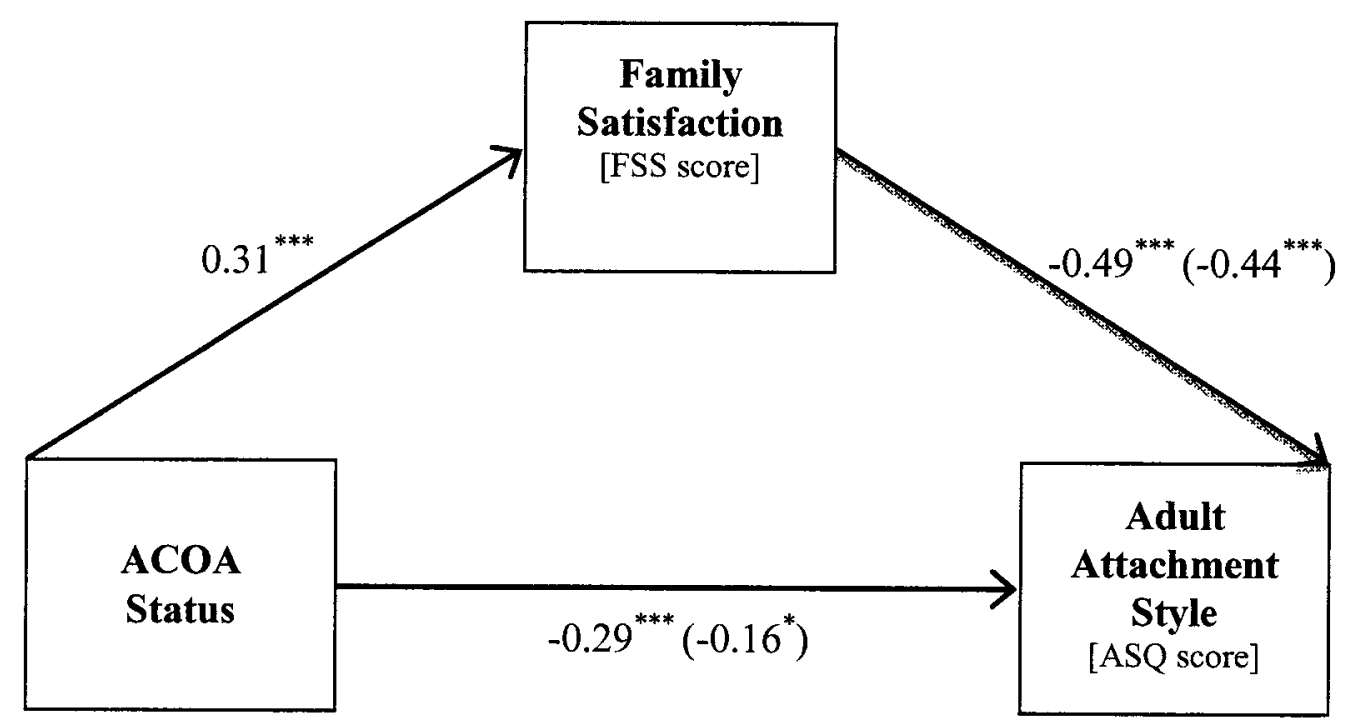

Figure 3. Hypothesized mediated model between ACOA status and adult attachment style, as partially mediated by family satisfaction.

${ }^{*} p<.05 ; * * * p \leq .001$ 


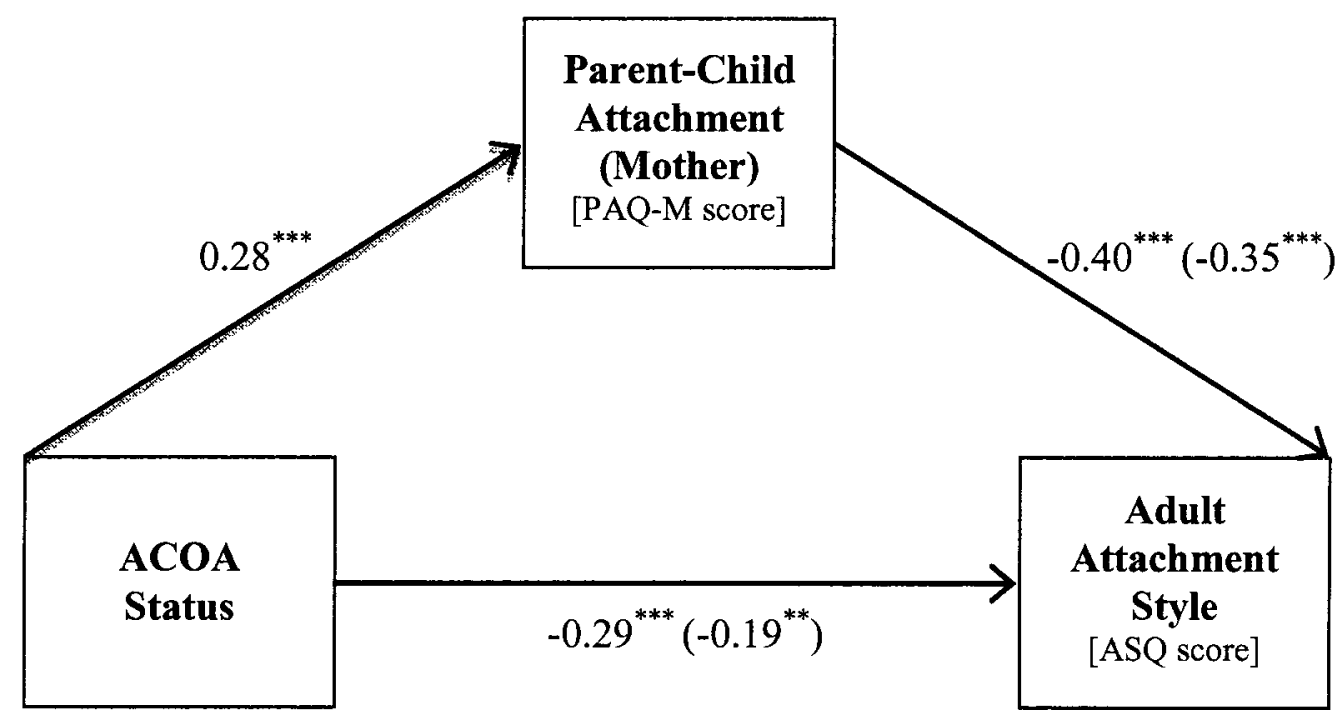

Figure 4. Hypothesized mediated model between ACOA status and adult attachment style, as partially mediated by maternal parent-child attachment.

$* * p<.01 ; * * * p<.001$ 


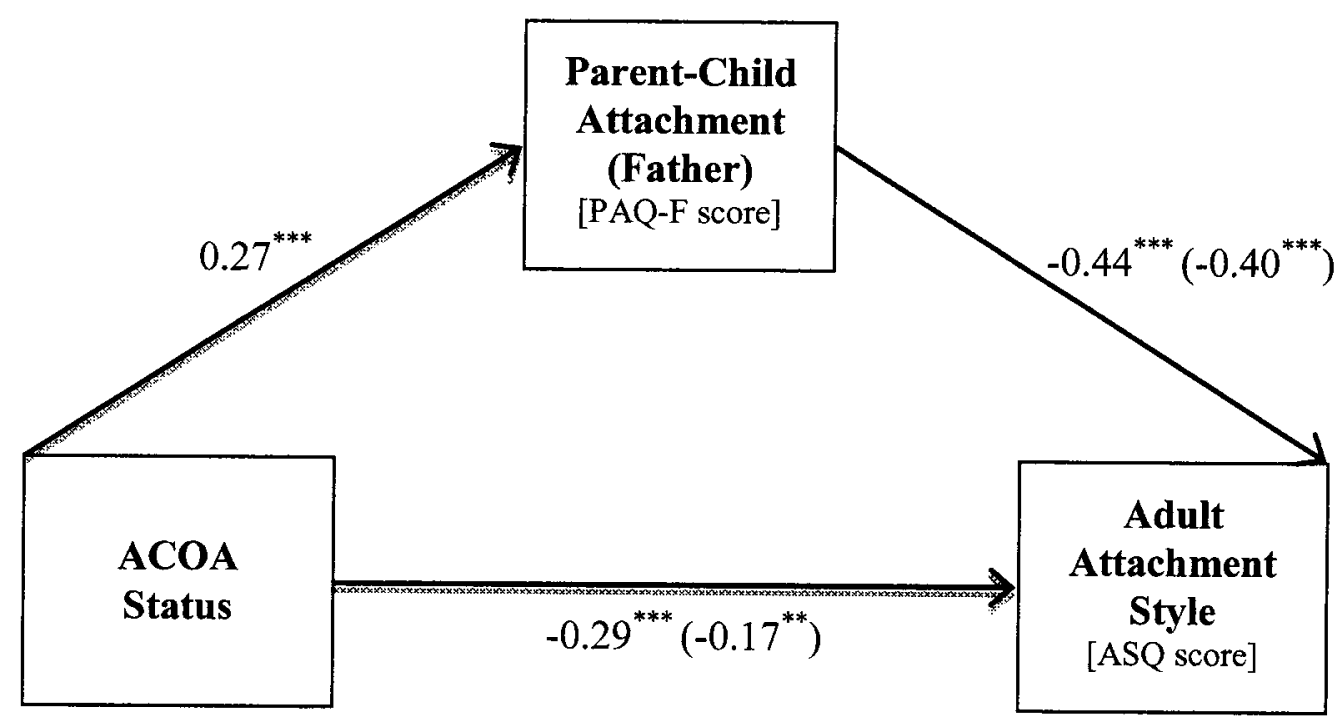

Figure 5. Hypothesized mediated model between ACOA status and adult attachment style, as partially mediated by paternal parent-child attachment.

$* * p<.01 ; * * * p<.001$ 


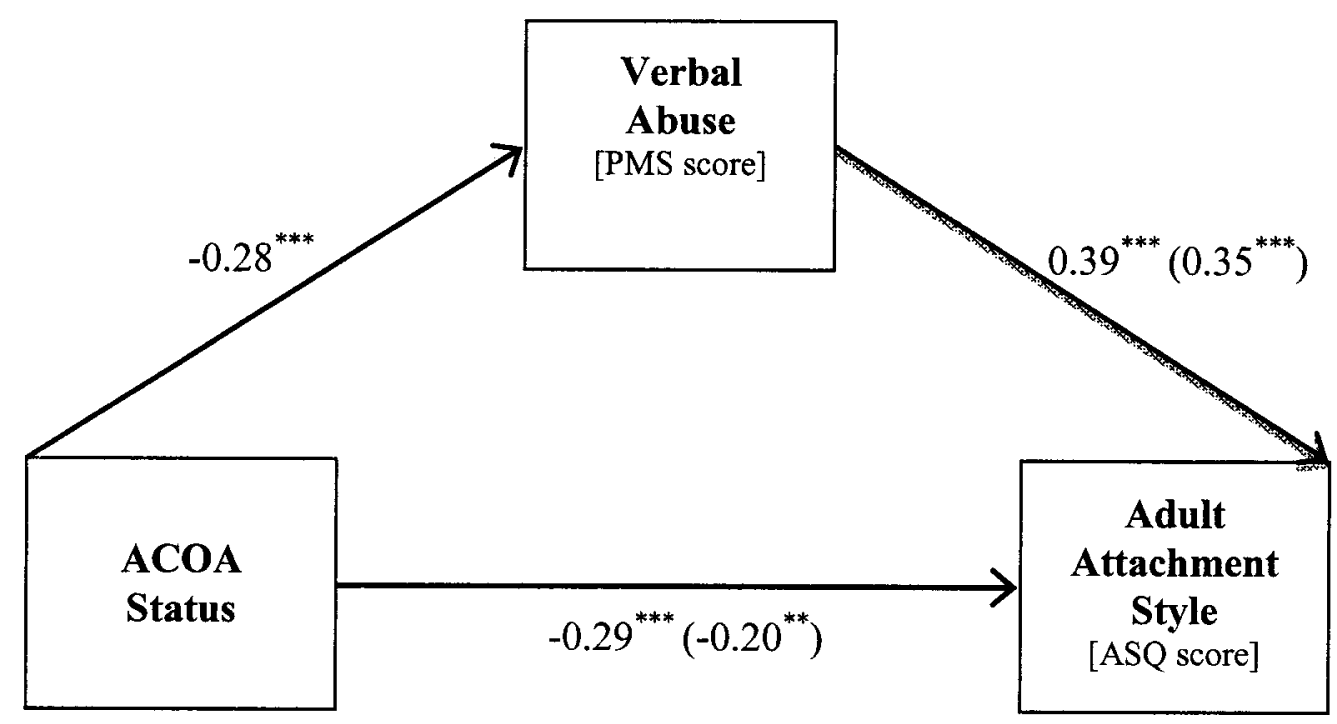

Figure 6. Hypothesized mediated model between ACOA status and adult attachment style, as partially mediated by verbal abuse.

$* * p<.01 ; * * * p<.001$ 


\section{APPENDIX A}

\section{Demographic Questionnaire}

Please fill out the following information.

1. Age:

2. Gender: Male

Female

3. Ethnicity:

Caucasian

Latin American

African American

Other

Native American

4. College Level:

Freshman

Graduate Student

Sophomore

Junior

Senior

5. Family Structure in childhood:

$\overline{\text { Never Married }}$

Intact (Parents Married)

Parents Separated

Parents Divorced/Not Remarried

Parents Remarried

6. How old were you when your parents separated or divorced?

Not applicable

7. Have you ever been concerned about your own substance use (i.e., alcohol or drug use)?

Yes

No

8. Has anyone else ever expressed concern about your substance use?

Yes

No

9. Have you ever received treatment for your substance use?

Yes

No

10. Have you ever received treatment for mental health concerns not related to substance use?

Yes

No

11. Did your mother experience significant problems with alcohol use or abuse?

Yes

No 
12. a. Did your mother experience significant problems with other substances (use or abuse)?

Yes

No

b. If yes, what substance(s) were used or abused?

13. Did your mother experience any other significant mental health concerns?

Yes

No

14. Did your father experience significant problems with alcohol use or abuse?

Yes

No

15. a. Did you father experience significant problems with other substances (use or abuse)?

Yes

No

b. If yes, what substance(s) were used or abused?

16. Did your father experience any other significant mental health concerns? Yes

No

17. Did either of your parents receive treatment for substance use or abuse?

Yes

No

18. Did either of your parents receive treatment for a mental health concern other than substance use or abuse?

Yes

No

19. Did anyone in your family ever receive treatment related to your parent's substance use or abuse?

Yes

No 


\section{APPENDIX B}

\section{Children of Alcoholics Screening Test (CAST)}

Please check the answer below that best describes your feelings, behavior, and experiences related to a parent's alcohol use. Take your time and be as accurate as possible. Answer all 30 questions by checking either "Yes" or "No."

\section{Yes No Questions}

1. Have you ever thought that one of your parents had a drinking problem?

2. Have you ever lost sleep because of a parent's drinking?

3. Did you ever encourage one of your parents to quit drinking?

4. Did you ever feel alone, scared, nervous, angry, or frustrated because a parent was not able to stop drinking?

5. Did you ever argue or fight with a parent when he or she was drinking?

6. Did you ever threaten to run away from home because of a parent's drinking?

7. Has a parent ever yelled at or hit you or other family members when drinking?

8. Have you ever heard your parents fight when one of them was drunk?

9. Did you ever protect another family member from a parent who was drinking?

10. Did you ever feel like hiding or emptying a parent's bottle of liquor?

11. Do many of your thoughts revolve around a problem drinking parent or difficulties that arise because of his or her drinking?

12. Did you ever wish that a parent would stop drinking?

13. Did you ever feel responsible for and guilty about a parent's drinking?

14. Did you ever fear that your parents would get divorced due to alcohol misuse?

15. Have you ever withdrawn from and avoided outside activities and friends because of embarrassment and shame over a parent's drinking problem?

16. Did you ever feel caught in the middle of an argument or fight between a problem drinking parent and your other parent?

17. Did you ever feel that you made a parent drink alcohol?

18. Have you ever felt that a problem drinking parent did not really love you?

19. Did you ever resent a parent's drinking?

20. Have you ever worried about a parent's health because of his or 


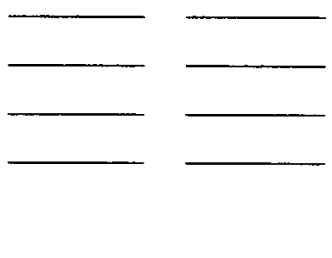

her alcohol use?

21. Have you ever been blamed for a parent's drinking?

22. Did you ever think your father was an alcoholic?

23. Did you ever wish your home could be more like the homes of your friends who did not have a parent with a drinking problem?

24. Did a parent ever make promises to you that he or she did not keep because of drinking?

25. Did you ever think your mother was an alcoholic?

26. Did you ever wish that you could talk to someone who could understand and help the alcohol-related problems in your family?

27. Did you ever fight with your brothers and sisters about a parent's drinking?

28. Did you ever stay away from home to avoid the drinking parent or your other parent's reaction to the drinking?

29. Have you ever felt sick, cried, or had a "knot" in your stomach after worrying about a parent's drinking?

30. Did you ever take over any chores and duties at home that were usually done by a parent before he or she developed a drinking problem? 


\section{APPENDIX C}

Attachment Style Questionnaire (ASQ)

Show how much you agree with each of the following items by rating them on this scale:

$1=$ totally disagree

$2=$ strongly disagree

$3=$ slightly disagree

$4=$ slightly agree

$5=$ strongly agree

$6=$ totally agree.

\section{$\begin{array}{llllll}1 & 2 & 3 & 4 & 5 & 6\end{array}$}

$\begin{array}{llllll}1 & 2 & 3 & 4 & 5 & 6\end{array}$

$\begin{array}{llllll}1 & 2 & 3 & 4 & 5 & 6\end{array}$

$\begin{array}{llllll}1 & 2 & 3 & 4 & 5 & 6\end{array}$

$\begin{array}{llllll}1 & 2 & 3 & 4 & 5 & 6\end{array}$

$\begin{array}{llllll}1 & 2 & 3 & 4 & 5 & 6\end{array}$

$\begin{array}{llllll}1 & 2 & 3 & 4 & 5 & 6\end{array}$

$\begin{array}{llllll}1 & 2 & 3 & 4 & 5 & 6\end{array}$

$\begin{array}{llllll}1 & 2 & 3 & 4 & 5 & 6\end{array}$

$\begin{array}{llllll}1 & 2 & 3 & 4 & 5 & 6\end{array}$

$\begin{array}{llllll}1 & 2 & 3 & 4 & 5 & 6\end{array}$

$\begin{array}{llllll}1 & 2 & 3 & 4 & 5 & 6\end{array}$

$\begin{array}{llllll}1 & 2 & 3 & 4 & 5 & 6\end{array}$

$\begin{array}{llllll}1 & 2 & 3 & 4 & 5 & 6\end{array}$

$\begin{array}{llllll}1 & 2 & 3 & 4 & 5 & 6\end{array}$

$\begin{array}{llllll}1 & 2 & 3 & 4 & 5 & 6\end{array}$

$\begin{array}{llllll}1 & 2 & 3 & 4 & 5 & 6\end{array}$
1.

Overall, I am a worthwhile person.

2. I am easier to get to know than most people.

3. I feel confident that other people will be there for me when I need them.

4. I prefer to depend on myself rather than other people.

5. I prefer to keep to myself.

6. To ask for help is to admit that you're a failure.

7. People's worth should be judged by what they achieve.

8. Achieving things is more important than building relationships.

9. Doing your best is more important than getting on with others.

10. If you've got a job to do, you should do it no matter who gets hurt.

11. It's important to me that others like me.

12. It's important to me to avoid doing things that others won't like.

13. I find it hard to make a decision unless I know what other people think.

14. My relationships with others are generally superficial.

15. Sometimes I think I am no good at all.

16. I find it hard to trust other people.

17. I find it difficult to depend on others. 
$\begin{array}{llllll}1 & 2 & 3 & 4 & 5 & 6\end{array}$

$\begin{array}{llllll}1 & 2 & 3 & 4 & 5 & 6\end{array}$

$\begin{array}{llllll}1 & 2 & 3 & 4 & 5 & 6\end{array}$

$\begin{array}{llllll}1 & 2 & 3 & 4 & 5 & 6\end{array}$

$\begin{array}{llllll}1 & 2 & 3 & 4 & 5 & 6\end{array}$

$\begin{array}{llllll}1 & 2 & 3 & 4 & 5 & 6\end{array}$

$\begin{array}{llllll}1 & 2 & 3 & 4 & 5 & 6\end{array}$

$\begin{array}{llllll}1 & 2 & 3 & 4 & 5 & 6\end{array}$

$\begin{array}{llllll}1 & 2 & 3 & 4 & 5 & 6\end{array}$

$\begin{array}{llllll}1 & 2 & 3 & 4 & 5 & 6\end{array}$

$\begin{array}{llllll}1 & 2 & 3 & 4 & 5 & 6\end{array}$

$\begin{array}{llllll}1 & 2 & 3 & 4 & 5 & 6\end{array}$

$\begin{array}{llllll}1 & 2 & 3 & 4 & 5 & 6\end{array}$

$\begin{array}{llllll}1 & 2 & 3 & 4 & 5 & 6\end{array}$

$\begin{array}{llllll}1 & 2 & 3 & 4 & 5 & 6\end{array}$

$\begin{array}{llllll}1 & 2 & 3 & 4 & 5 & 6\end{array}$

$\begin{array}{llllll}1 & 2 & 3 & 4 & 5 & 6\end{array}$

$\begin{array}{llllll}1 & 2 & 3 & 4 & 5 & 6\end{array}$

$\begin{array}{llllll}1 & 2 & 3 & 4 & 5 & 6\end{array}$

$\begin{array}{llllll}1 & 2 & 3 & 4 & 5 & 6\end{array}$

$\begin{array}{llllll}1 & 2 & 3 & 4 & 5 & 6\end{array}$

$\begin{array}{llllll}1 & 2 & 3 & 4 & 5 & 6\end{array}$

$\begin{array}{llllll}1 & 2 & 3 & 4 & 5 & 6\end{array}$
18. I find that others are reluctant to get as close as I would like.

19. I find it relatively easy to get close to other people.

20. I find it easy to trust others.

21. I feel comfortable depending on other people.

22. I worry that others won't care about me as much as I care about them.

23. I worry about people getting too close.

24. I worry that I won't measure up to other people.

25. I have mixed feelings about being close to others.

26. While I want to get close to others, I feel uneasy about it.

27. I wonder why people would want to be involved with me.

28. It's very important to me to have a close relationship.

29. I worry a lot about my relationships.

30. I wonder how I would cope without someone to love me.

31. I feel confident about relating to others.

32. I often feel left out or alone.

33. I often worry that I do not really fit in with other people.

34. Other people have their own problems, so I don't bother them with mine.

35. When I talk over my problems with others, I generally feel ashamed or foolish.

36. I am too busy with other activities to put much time into relationships.

37. If something is bothering me, others are generally aware and concerned.

38. I am confident that other people will like and respect me.

39. I get frustrated when others are not available when I need them.

40. Other people often disappoint me. 


\section{APPENDIX D \\ Parent-Child Conflict Tactics Scale (CTSPC)}

Here is a list of things your parents might have done when you had a conflict or disagreement with them. We would like you to try and remember what went on your worst year during the time you were living at home. Please indicate how often your parents did it.

Never Once Twice 3- 6- 11- $>20$

$$
5 \quad 10 \quad 20
$$

1. Hit me with a fist or kicked me hard.

2. Grabbed me around the neck and choked me.

3. Beat me up, that is he/she hit me over and over as hard as he/she could.

\section{Burned or scalded me on purpose.}

5. Hit me on some other part of the body besides the bottom with something like a belt, hairbrush, a stick or some other hard object.

\section{Threatened me with a knife or gun.}

7. Threw or knocked me down.

8. Slapped me on the face or head or ears.

\begin{tabular}{llllllll} 
Mother & 0 & 1 & 2 & 3 & 4 & 5 & 6 \\
\cline { 2 - 8 } Father & 0 & 1 & 2 & 3 & 4 & 5 & 6 \\
\hline
\end{tabular}

\begin{tabular}{llllllll} 
Mother & 0 & 1 & 2 & 3 & 4 & 5 & 6 \\
\cline { 2 - 7 } Father & 0 & 1 & 2 & 3 & 4 & 5 & 6 \\
\hline
\end{tabular}

Mother

Father

$\begin{array}{lllllll}0 & 1 & 2 & 3 & 4 & 5 & 6\end{array}$

Mother

\begin{tabular}{lllllll}
\hline 0 & 1 & 2 & 3 & 4 & 5 & 6 \\
\hline
\end{tabular}

Father

\begin{tabular}{lllllll}
0 & 1 & 2 & 3 & 4 & 5 & 6 \\
\hline 0 & 1 & 2 & 3 & 4 & 5 & 6 \\
\hline
\end{tabular}

Mother \begin{tabular}{lllllll}
0 & 1 & 2 & 3 & 4 & 5 & 6 \\
\hline
\end{tabular}

Father $\begin{array}{llllllll}0 & 1 & 2 & 3 & 4 & 5 & 6\end{array}$

\begin{tabular}{llllllll} 
Mother & 0 & 1 & 2 & 3 & 4 & 5 & 6 \\
\cline { 2 - 7 } Father & 0 & 1 & 2 & 3 & 4 & 5 & 6 \\
\hline
\end{tabular}

\begin{tabular}{llllllll} 
Mother & 0 & 1 & 2 & 3 & 4 & 5 & 6 \\
\cline { 2 - 8 } Father & 0 & 1 & 2 & 3 & 4 & 5 & 6 \\
\hline
\end{tabular}

\begin{tabular}{llllllll} 
Mother & 0 & 1 & 2 & 3 & 4 & 5 & 6 \\
\cline { 2 - 8 } Father & 0 & 1 & 2 & 3 & 4 & 5 & 6 \\
\hline
\end{tabular}




\section{APPENDIX E}

\section{Psychological Maltreatment Scale (PMS)}

Verbal arguments and punishment can range from quiet disagreements to yelling, insulting, and more severe behaviors. When you were living at home, how often did the following happen to you in the average year? Answer for your mother and your father.

$$
\begin{array}{llllll}
\text { Never Once Twice } & 3- & 6- & 11- & >20 \\
5 & 10 & 20 &
\end{array}
$$

1. Yell at you.

2. Insult you.

3. Criticize you.

4. Try to make you feel

\begin{tabular}{|c|c|c|c|c|c|c|c|}
\hline Mother & 0 & 1 & 2 & 3 & 4 & 5 & 6 \\
\hline Father & 0 & 1 & 2 & 3 & 4 & 5 & 6 \\
\hline
\end{tabular}
guilty.

\begin{tabular}{|c|c|c|c|c|c|}
\hline Mother & 0 & 1 & 2 & 3 & 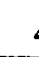 \\
\hline ather & 0 & 1 & 2 & 3 & \\
\hline
\end{tabular}

Mother

Father

\begin{tabular}{lllllll}
0 & 1 & 2 & 3 & 4 & 5 & 6 \\
\hline 0 & 1 & 2 & 3 & 4 & 5 & 6 \\
\hline
\end{tabular}

\begin{tabular}{llllllll} 
Mother & 0 & 1 & 2 & 3 & 4 & 5 & 6 \\
\cline { 2 - 8 } Father & 0 & 1 & 2 & 3 & 4 & 5 & 6 \\
\hline
\end{tabular}

5. Ridicule or humiliate you. Mother

Father

\begin{tabular}{lllllll}
0 & 1 & 2 & 3 & 4 & 5 & 6 \\
\hline 0 & 1 & 2 & 3 & 4 & 5 & 6 \\
\hline
\end{tabular}

6. Embarrass you in front of others.

7. Make you feel like you were a bad person.
Mother

Father

\begin{tabular}{lllllll}
0 & 1 & 2 & 3 & 4 & 5 & 6 \\
\hline 0 & 1 & 2 & 3 & 4 & 5 & 6 \\
\hline
\end{tabular}

Mother

Father

\begin{tabular}{lllllll}
0 & 1 & 2 & 3 & 4 & 5 & 6 \\
\hline 0 & 1 & 2 & 3 & 4 & 5 & 6
\end{tabular}




\section{APPENDIX F}

Family Adaptability and Cohesion Evaluation Scales (FACES-IV)

For the following questions, please choose the best option that applies to YOUR family.

\begin{tabular}{|c|c|c|c|c|}
\hline 1 & 2 & 3 & 4 & 5 \\
\hline DOES NOT & SLIGHTLY & SOMEWHAT & GENERALLY & VERY WELL \\
\hline $\begin{array}{l}\text { describe our } \\
\text { Family at all }\end{array}$ & $\begin{array}{c}\text { describes our } \\
\text { family }\end{array}$ & $\begin{array}{c}\text { describes our } \\
\text { family }\end{array}$ & $\begin{array}{c}\text { describes our } \\
\text { family }\end{array}$ & $\begin{array}{c}\text { describes our } \\
\text { family }\end{array}$ \\
\hline
\end{tabular}

1. Family members are involved in each others lives.

2. Our family tries new ways of dealing with problems.

3. We get along better with people outside our family than inside.

4. We spend too much time together.

5. There are strict consequences for breaking the rules in our family.

6. We never seem to get organized in our family.

7. Family members feel very close to each other.

8. Parents equally share leadership in our family.

9. Family members seem to avoid contact with each other when at home.

10. Family members feel pressured to spend most free time together.

11. There are clear consequences when a family member does something wrong.

12. It is hard to know who the leader is in our family.

13. Family members are supportive of each other during difficult times.

14. Discipline is fair in our family.

15. Family members know very little about the friends of other family members.

16. Family members are too dependent on each other.

17. Our family has a rule for almost every possible situation.

18. Things do not get done in our family. 
19. Family members consult other family members on important decisions.

20. My family is able to adjust to change when necessary.

21. Family members are on their own when there is a problem to be solved.

22. Family members have little need for friends outside the family.

23. Our family is highly organized.

24. It is unclear who is responsible for things (chores, activities) in our family.

25. Family members like to spend some of their free time with each other.

26. We shift household responsibilities from person to person.

27. Our family seldom does things together.

28. We feel too connected to each other.

29. Our family becomes frustrated when there is a change in our plans or routines.

30. There is no leadership in our family.

31. Although family members have individual interests, they still participate in family activities.

32. We have clear rules and roles in our family.

33. Family members seldom depend on each other.

34. We resent family members doing things outside the family.

35. It is important to follow the rules in our family.

36. Our family has a hard time keeping track of who does various household tasks.

37. Our family has a good balance of separateness and closeness.

38. When problems arise, we compromise.

39. Family members mainly operate independently.

40. Family members feel guilty if they want to spend time away from the family. 
41. Once a decision is made, it is very difficult to modify that decision.

42. Our family feels hectic and disorganized. 


\section{APPENDIX G \\ Family Satisfaction Scale (FSS)}

For the following questions, please choose the best option that applies to YOUR family.

\begin{tabular}{|c|c|c|c|c|}
\hline 1 & 2 & 3 & 4 & 5 \\
\hline DOES NOT & $\underline{\text { SLIGHTLY }}$ & SOMEWHAT & GENERALLY & VERY WELL \\
\hline $\begin{array}{l}\text { describe our } \\
\text { Family at all }\end{array}$ & $\begin{array}{l}\overline{\text { describes our }} \\
\text { family }\end{array}$ & $\begin{array}{c}\text { describes our } \\
\text { family }\end{array}$ & $\begin{array}{c}\text { describes our } \\
\text { family }\end{array}$ & $\begin{array}{c}\text { describes our } \\
\text { family }\end{array}$ \\
\hline
\end{tabular}

How satisfied are you with:

1. The degree of closeness between family members.

2. Your family's ability to cope with stress.

3. Your family's ability to be flexible.

4. Your family's ability to share positive experiences.

5. The quality of communication between family members.

6. Your family's ability to resolve conflicts.

7. The amount of time you spend together as a family.

8. The way problems are discussed.

9. The fairness of criticism in your family.

10. Family members concern for each other. 


\section{APPENDIX H}

Parental Attachment Questionnaire

\begin{tabular}{|c|c|c|c|c|}
\hline $\begin{array}{c}1 \\
\text { Not at all } \\
(0-10 \%)\end{array}$ & $\begin{array}{c}2 \\
\text { Somewhat } \\
(11-35 \%)\end{array}$ & $\begin{array}{c}3 \\
\text { A Moderate } \\
\text { Amount } \\
(\mathbf{3 6 - 6 5 \% )}\end{array}$ & $\begin{array}{c}4 \\
\text { Quite a Bit } \\
(66-90 \%)\end{array}$ & $\begin{array}{c}5 \\
\text { Very Much } \\
(91-100 \%)\end{array}$ \\
\hline
\end{tabular}

\section{In general, my mother/father....}

M F

1. is someone I can count on to listen to me.

- 2. supports my goals and interests.

3. sees the world differently than I do.

_ $\quad$ 4. understands my problems and concerns.

5. respects my privacy.

6. limits my independence.

7. gives me advice when I ask for it.

8. takes me seriously.

9. likes me to make my own decisions.

10. criticizes me.

11. tells me what to think or how to feel

12. gives me attention when I want it.

13. is someone I can talk to about anything.

M F

14. has no idea what I am feeling or thinking.

15. lets me try new things out and learn on my own.

16. is too busy to help me.

17. has trust and confidence in me.

18. tries to control my life.

19. protects me from danger and difficulty.

20. ignores what I have to say.

21. is sensitive to my feelings and needs.

22. is disappointed in me.

23. gives me advice whether or not I want it.

24. respect my decisions, even if they don't agree.

25. does things for me which I would rather do for myself.

26. is someone whose expectations I feel I have to meet.

27. treats me like a younger child. 


\begin{tabular}{|c|c|c|c|c|}
\hline $\begin{array}{c}1 \\
\text { Not at all } \\
(0-10 \%)\end{array}$ & $\begin{array}{c}2 \\
\text { Somewhat } \\
(11-35 \%)\end{array}$ & $\begin{array}{c}3 \\
\text { A Moderate } \\
\text { Amount } \\
(36-65 \%)\end{array}$ & $\begin{array}{c}4 \\
\text { Quite a Bit } \\
(66-90 \%)\end{array}$ & $\begin{array}{c}5 \\
\text { Very Much } \\
(91-100 \%)\end{array}$ \\
\hline
\end{tabular}

During time spent together, my mother/father was someone...

$\mathbf{M} \quad \mathbf{F}$

28. I looked forward to seeing.

29. With whom I argued.

30. With whom I felt comfortable.

31 . Who made me angry.

32. I wanted to be with all the time.

33. Towards whom I felt cool and distant.

34. Who got on my nerves.

35. Who made me feel guilty and anxious.

36. I liked telling about what I have done recently.

37. For whom I felt feelings of love.

38. I tried to ignore.

39. To whom I told my most personal thoughts and feelings.

40. I liked being with.

41. I didn't want to tell what has been going on in my life.

Following time spent together, I leave my mother/father...

M F

42. With warm and positive feelings

43. Feeling let down and disappointed.

When I have a serious problem or an important decision to make...

M F

44. I look to my family for help.

45. I go to a therapist, school counselor, or clergy (priest, rabbi, or minister).

46. I think about what my mom or dad might say.

47. I work it out on my own, without help from anyone.

48. I talk it over with a friend.

49. I know that my family will know what I should do.

50. I ask my family for help if my friends can't help.

When I go to my mother/father for help...

M F 
51. I feel more sure of my ability to handle the problems on my own.

52. I continue to feel unsure of myself.

53. I feel that I would have gotten more understanding from a friend.

54. I feel sure that things will work out as long as I follow my parent's advice. 55. I am disappointed with their response.

\begin{tabular}{|c|c|c|c|c|}
\hline $\begin{array}{c}1 \\
\text { Not at all } \\
(0-10 \%)\end{array}$ & $\begin{array}{c}2 \\
\text { Somewhat } \\
(11-35 \%)\end{array}$ & $\begin{array}{c}3 \\
\text { A Moderate } \\
\text { Amount } \\
(36-65 \%)\end{array}$ & $\begin{array}{c}4 \\
\text { Quite a Bit } \\
(66-90 \%)\end{array}$ & $\begin{array}{c}5 \\
\text { Very Much } \\
(91-100 \%)\end{array}$ \\
\hline
\end{tabular}




\section{APPENDIX I}

\section{Rosenberg Self-Esteem Scale}

Instructions: Below is a list of statements dealing with your general feelings about yourself. If you strongly agree, circle SA. If you agree with the statement, circle $\mathbf{A}$. If you disagree, circle D. If you strongly disagree, circle SD.

1. On the whole, I am satisfied with myself.

2. At times, I think I am no good at all.

3. I feel that I have a number of good qualities.

4. I am able to do things as well as most other people.

5. I feel I do not have much to be proud of.

6. I certainly feel useless at times.

7. I feel that I'm a person of worth, at least on an equal plane with others.

8. I wish I could have more respect for myself.

9. All in all, I am inclined to feel that I am a failure.

10. I take a positive attitude toward myself.
SA A D SD

SA A D SD

SA A D SD

SA A D SD

SA A D SD

SA A D SD

SA A D SD

SA A D SD

SA A D SD

SA A D SD 


\section{APPENDIX J}

\section{Informed Consent}

You are invited to participate in a research study conducted by Dr. Anu Sharma of the EIU Psychology Department and Kristina Decker, a Master's degree candidate in the Clinical Psychology M.A. program at EIU. The purpose of this study is to examine the relationship between childhood family experiences and adult functioning. These findings can potentially help researchers and clinicians better understand the long term impact of different types of childhood family experiences.

If you agree to participate in this study, you will be asked to complete an online questionnaire, which is expected to take approximately 30 minutes to complete. You must be at least 18 years old to participate. Participation is fully voluntary, and you may withdraw from the study at any time without penalty. The answers you provide will remain anonymous and used only for research purposed. There are no risks associated with this study. Students enrolled in Introductory Psychology will receive course credit for their participation.

Should you have any questions regarding your participation in this study, or any questions about the study in general, you are invited to contact the lead researcher via email at asharma@eiu.edu.

If you have any questions or concerns about the treatment of human participants in this study, you may call or write: Institutional Review Board, Eastern Illinois University, 600 Lincoln Ave., Charleston, IL 61920. Telephone: (217) 581- 8576. Email: eiuirb@www.eiu.edu.

You will be given the opportunity to discuss any questions about your rights as a research participant with a member of the IRB. The IRB is an independent committee composed of members of the University community, as well as lay members of the community not connected with EIU. The IRB has reviewed and approved this study.

By clicking the "I consent" icon below, you are indicating that you are at least 18 years old and have read, understand, and accept the terms outlined above. 